\title{
Arctic sea ice decline weakens the Atlantic Meridional Overturning Circulation
}

Florian Sévellec ${ }^{1}$, Alexey V. Fedorov ${ }^{2}$, and Wei Liu ${ }^{2}$

\author{
${ }^{1}$ Ocean and Earth Science, University of Southampton, Southampton, UK \\ ${ }^{2}$ Department of Geology and Geophysics, Yale University, New Haven, Connecticut
}

The ongoing decline of Arctic sea ice ${ }^{1,2}$ exposes the ocean to anomalous surface heat and freshwater fluxes, resulting in positive buoyancy anomalies that can affect ocean circulation. In this study, we use an optimal flux perturbation framework and comprehensive climate model simulations to estimate the sensitivity of the Atlantic meridional overturning circulation (AMOC) to such buoyancy forcing over the Arctic and globally, and more generally to sea ice decline. It is found that on decadal timescales flux anomalies over the subpolar North Atlantic have the largest impact on the AMOC, while on multi-decadal timescales (longer than 20 years), flux anomalies in the Arctic become more important. These positive buoyancy anomalies spread to the North Atlantic, weakening the AMOC and its poleward heat transport. Therefore, the Arctic sea ice decline may explain the suggested slow-down of the AMOC and the "Warming Hole"3,4 persisting in the subpolar North Atlantic. 


\section{Observations of climate change in the Arctic ocean and the North Atlantic}

Global climate change is now affecting various components of the Earth's climate system. In particular, the extent of Arctic sea ice has been declining over the past several decades ${ }^{1,2}$, with an annual-mean areal reduction of $\sim 20 \%$ since 1980 (Fig. 1) and even stronger decrease in September $(\sim 30 \%)$. At the same time, the Atlantic Meridional Overturning Circulation (AMOC), a crucial component of oceanic circulation monitored over the past decade by the RAPID array ${ }^{5}$ at $26.5^{\circ} \mathrm{N}$, is arguably slowing down ${ }^{6}$ at a rate as high as $0.4 \mathrm{~Sv} \mathrm{yr}^{-1}$ (Fig. 2a). Although the attribution of this recent AMOC slow-down remains an open question ${ }^{7,8}$ in view of oceanic natural decadal variability $^{9}$, indirect evidence based on the proxies of AMOC strength ${ }^{4}$ supports the hypothesis that the AMOC is gradually weakening (Fig. 2b) as part of ongoing climate change. Complementary to these present-day observations, numerical experiments using state-of-the-art climate models under future $\mathrm{CO}_{2}$ emission scenarios consistently predict a gradual AMOC slow-down during this century ${ }^{10}$.

The long-term AMOC decline has been conjectured to cause the so-called Warming Hole persisting in the subpolar North Atlantic ${ }^{3,4}$ especially pronounced between 50 and $60^{\circ} \mathrm{N}$ (Fig. $2 \mathrm{c}$ and S1). Indeed, the weakening of oceanic poleward heat transport associated with this decline is arguably the most likely explanation for why this region is warming at a slower rate than the rest of the globe (or possibly even cooling down). This relative cooling moderates local impacts of anthropogenically forced climate change over the ocean ${ }^{11}$.

Nevertheless, beyond general conceptual understanding of this mechanism ${ }^{12}$, there exists 
no agreement on the exact causes of the AMOC slow-down and the Warming Hole, nor their attribution to a particular external forcing. The main goal of the present study is to investigate whether these phenomena could be driven by the ongoing Arctic climate change.

\section{AMOC sensitivity to Arctic surface heat and freshwater fluxes}

Because of its role in modulating the climate of the North Atlantic ${ }^{13}$, the AMOC has been studied by many different methods ranging from observational proxies ${ }^{4,14}$ to high-resolution simulations ${ }^{15}$ with general circulation models (GCMs) to adjoint ocean modeling ${ }^{16}$. The last method can estimate the sensitivity of the AMOC to past disturbances in the forcing field ${ }^{17,18}$ and provide a dynamical attribution of AMOC changes ${ }^{19}$ by integrating linearized equations of motion backward in time. Here, we first apply such an adjoint modeling approach to examine how anomalies in global ocean surface fluxes of heat and freshwater affect the AMOC at $50^{\circ} \mathrm{N}$. Specifically, to assess the AMOC sensitivity to spatially varying but constant in time surface fluxes, we compute optimal patterns of surface fluxes (also called flux linear optimal perturbations, or flux LOPs) that modify the AMOC at $50^{\circ} \mathrm{N}$ the most over given time intervals (Fig. 3). The computations use a state-of-the-art ocean general circulation model $\left(\mathrm{GCM}, \mathrm{NEMO}^{20}\right)$ in a $2^{\circ}$ realistic configuration (ORCA2), together with its tangent linear and adjoint versions ${ }^{21}$ (Methods). The model reproduces an ocean mean climatological state in a good agreement with the observations (Fig. S2).

The duration of the imposed fluxes is varied in the numerical computations from 10 to $200 \mathrm{yr}$. We find that for fluxes shorter than $\sim 100$ years the AMOC sensitivity exhibits a weak oscillatorylike behavior (Fig. 4a and b). It is related to the existence in the system of a 24-yr oscillatory 
ocean mode associated with large-scale baroclinic (thermal) Rossby waves propagating across the North Atlantic ${ }^{22}$. Save for these weak variations, flux perturbations persisting for longer time have greater impacts on the AMOC intensity. For example, the impact on the AMOC volume transport of optimal surface fluxes that last for two centuries is about three times as large as those lasting for one decade.

To compare the AMOC sensitivity to surface fluxes applied over different geographical regions, we split the global ocean into three areas - the Arctic ocean, the North Atlantic, and the rest of the ocean (Fig. 4, insert). The boundaries of the Arctic ocean are set following the definition of the International Hydrographic Organization, which includes the Hudson Bay, the northernmost part of the Labrador Sea, and the Greenland and Iceland Seas, but to simplify the computations our definition uses a straightened Arctic - Atlantic boundary, incorporating the Norwegian Sea into the Arctic region (this modification affects the results very little). As our computations of the optimal flux perturbations are linear, the sum of sensitivities to fluxes applied over separate regions give the AMOC total sensitivity.

From this analysis we find that, whereas on a decadal timescale the AMOC at $50^{\circ} \mathrm{N}$ is most sensitive to heat/freshwater flux perturbations over the North Atlantic, on multi-decadal and longer timescales it is most sensitive to Arctic perturbations (Fig. 4c and d). This is one of the main findings of our study. In fact, surface flux perturbations lasting for one century and imposed over the Arctic region are twice as effective in modifying the AMOC as those imposed over the North Atlantic, even though the surface area of the latter region is about three times greater. 
Examining in more detail the structure of the optimal fluxes (Fig. 3) suggests that the sensitivity patterns for heat and freshwater fluxes are fairly similar, which indicates that it is their effect on ocean buoyancy that matters rather than the type of perturbation. The amplitude of the optimal patterns is greatest north of $50^{\circ} \mathrm{N}$, which indicates that on decadal to centennial timescales the AMOC at $50^{\circ} \mathrm{N}$ is only weakly sensitive to surface fluxes over the subtropical North Atlantic or other remote locations.

On a decadal timescale, the maximum sensitivity occurs in the subpolar North Atlantic in the Labrador and Irminger seas and along the east coast of Greenland (Fig. 3a and e). These locations have been previously highlighted as particularly efficient regions for stimulating AMOC decadal variability in the same ocean model ${ }^{14,23}$, as it provides fast routes to influence the deep ocean. For surface fluxes persisting over multi-decadal to centennial timescales, the area of high sensitivity spreads into the Arctic (Fig. 3b-c and f-g) eventually developing an approximately uniform pattern over the entire Arctic ocean with a residual signature evident along the east coast of Greenland (Fig. $3 \mathrm{~d}$ and h). This nearly uniform pattern suggests that it is the net surface warming or freshening of the Arctic that matters the most, rather than particular geographical details of the imposed flux anomalies. Thus, the Arctic ocean can become the primary driver of AMOC weakening on multidecadal to centennial timescales (Fig. $4 \mathrm{c}$ and d). The optimal surface fluxes act to reduce the model AMOC volume transport, and hence oceanic meridional heat transport in the entire North Atlantic, both in high and low latitudes (Fig. S3).

On these longer timescales the mechanism by which the Arctic affects the AMOC includes 
southward advection of buoyancy anomalies, which affect the deep ocean through several deep convection sites in the Nordic Seas and the North Atlantic simulated by the ocean model (Fig. S4). In particular, advection by the East Greenland current through the Denmark strait and the GreenlandIceland ridge overflow appear to be important. The subsequent ocean adjustment that involves Kelvin and thermal Rossby waves ${ }^{23}$ modifies the AMOC across the basin. Thus, the Arctic ocean acts as a reservoir of positive buoyancy anomalies that sustain the weakening of the AMOC when advected downstream from the Arctic into the North Atlantic.

To summarize, the adjoint sensitivity analysis indicates that surface buoyancy anomalies in the North Atlantic impact the AMOC on shorter, decadal timescales, but their efficiency is reduced by a gradual buoyancy loss to the rest of the Atlantic through ocean adjustment due to waves and advective processes. In contrast, on longer timescales buoyancy anomalies can accumulate in the Arctic ocean, causing a persistent AMOC slow-down.

These results are particularly important in the context of anthropogenic global warming and more specifically Arctic climate change. Indeed, the ongoing loss of Arctic sea ice ${ }^{1,2}$ increases the area of open ocean (Fig. 1). During summer this expansion leads to a strong anomalous solar heat flux into the ocean over a large part of the Arctic, since seawater has a much lower albedo than ice. At the same time, the decrease of water storage ${ }^{24}$ in sea ice and the Greenland ice sheet, in addition to changes in the atmospheric hydrological cycle ${ }^{25}$, increases net freshwater flux into the Arctic ocean. These observed changes should generate anomalies in ocean heat and freshwater fluxes over the Arctic that our analysis suggests could cause an AMOC slow-down. 


\section{Attributing the AMOC decline to surface flux anomalies in the Arctic}

To connect the AMOC slow-down suggested by the observations ${ }^{4,6}$ to changes in the Arctic more directly we have examined anomalies in oceanic heat and freshwater fluxes that developed over the last several decades (Fig. 5a and b). Large uncertainties in surface fluxes over the Arctic ${ }^{26}$ imply that one has to carefully reconstruct the fluxes from a combination of available measurements and atmospheric reanalyses (Methods). These estimated or reconstructed fluxes indicate a net warming and freshening of the Arctic ocean at a rate of $+8.2 \mathrm{~W} \mathrm{~m}^{-2}$ and $+8.7 \mathrm{~cm} \mathrm{yr}^{-1}$, respectively. The signs of these anomalies coincide with those of the optimal surface fluxes that weaken the AMOC. To quantify the effects of these flux anomalies, we now impose them as constant in time surface flux perturbations within the forward ocean model. These forward integrations exhibit an AMOC slow-down at a typical rate of $0.5-1 \mathrm{~Sv}$ per decade, asymptotically approaching a $4 \mathrm{~Sv}$ reduction after one century (Fig. 5c).

In addition, again taking advantage of the linear framework, we assess the separate contribution of each geographical region by conducting similar experiments but imposing the reconstructed anomalous surface fluxes only over the region of interest. We find that about $75 \%$ of the AMOC decline is driven by Arctic changes, whereas the remaining part is associated with changes in the North Atlantic (mainly in the subpolar region). Note that the contribution to the AMOC slow-down of fluxes over the Norwegian Sea, included in our definition of the Arctic, is less than $7 \%$. Furthermore, $90 \%$ of the total AMOC slow-down can be attributed to Arctic heat flux anomalies and the rest to freshwater fluxes (Fig. S5). This confirms that the Arctic sea ice retreat, exposing the ocean to direct solar radiation and generating positive heat flux anomalies, is critical in controlling 
the AMOC strength in this ocean model.

It is important to note that ocean adjustment to the imposed surface flux anomalies is nonlocal and involves the entire Atlantic basin. For example, the AMOC slow-down manifests in the decrease of oceanic meridional heat transport in the subtropics, for example at $25^{\circ} \mathrm{N}$ (Fig. $5 \mathrm{~d}$ ), close to the location of the RAPID array. This weakening of oceanic heat transport in low latitudes is controlled primarily from the Arctic ocean, with little contribution from other regions (Fig. 5d). It is the Arctic heat flux anomalies that contribute to the changes in oceanic heat transport the most - their effect is an order of magnitude stronger than that of freshwater flux anomalies (Fig. 4c and d). These results demonstrate the potentially crucial role of the Arctic ocean for the climate of the North Atlantic. Indeed, our findings imply that Arctic climate change, by weakening the AMOC, can cool parts of the subpolar/mid-latitude North Atlantic remotely, providing a negative feedback to global warming over the ocean. In contrast, heat fluxes over the North Atlantic would not be as efficient in weakening the AMOC and its heat transport (Fig. 5a-d), and would tend to increase sea surface temperature (SST) in this region. Therefore, the observed Warming Hole in the North Atlantic is consistent with the AMOC slow-down driven by Arctic climate change.

\section{Sea ice retreat as the driver of AMOC weakening in a global climate model}

To further validate our results we have conducted two perturbation experiments using a comprehensive global climate model (CESM ${ }^{27}$, Methods) in which we modify sea ice radiative budget with the aim to reproduce the spatial structure and magnitude of the Arctic sea ice decline recorded over the past decades (Fig. 6a-c and S6a,b). The experiments use two complementary approaches that 
work by creating positive radiation imbalance at the sea ice surface in the Arctic, predominantly during summer. The first approach is based on reducing the longwave (LW) emissivity of sea ice, while the second one - on reducing the shortwave (SW) reflectivity of sea ice and overlying snow. The experiments start from the control simulation; then a perturbation to sea ice radiative properties is applied instantaneously (Fig. 6e) and maintained for the duration of integration (200 years), without any other imposed changes. Both approaches produce quantitatively similar results and cause melting and contraction of sea ice, greatest at the end of summer but smaller during winter (Fig. 6c).

Within the first several years of the perturbed simulations Arctic sea ice contracts and warm SST anomalies develop around the ice margins (Fig. 6 and Fig. S6). The ice contraction and ocean warming are particularly intense in September (Fig. S7). Subsequently, buoyancy anomalies, due to both warming and freshening, accumulate in the Arctic. In response, the AMOC gradually weakens by about 50\% during the next 100 years (Fig. 6f), which is generally consistent with the results of the forward ocean model (Fig. 5c). The mismatch between the long adjustment timescale for the AMOC and a shorter one for sea ice is indicative of the gradual ocean adjustment to the spreading buoyancy anomalies. A further analysis shows that over the first 40 years of the experiments heat flux anomalies play the primary role in weakening the AMOC, but subsequently freshwater that gradually accumulates in the Arctic becomes as important. The increased role of freshwater anomalies explains a stronger AMOC weakening in the experiments than suggested by the adjoint sensitivity study. 
As expected, the weakening of the AMOC is accompanied by the reduction of oceanic meridional heat transport (Fig. S8), leading to a roughly $1-2^{\circ} \mathrm{C}$ cooling in the subpolar/mid-latitude North Atlantic (Fig. 6d) that resembles the observed Warming Hole (Fig. 2c). The nearly identical results of the two experiments, using different perturbations to the radiation balance, confirm the robustness of our main conclusions.

Note that direct comparison between the observations and these climate modelling experiments is somewhat limited by two factors: (i) the perturbations to sea ice radiative balance are applied instantaneously; and (ii) the model ocean reaches a quasi-equilibrium by the end of integrations whereas the real ocean is still adjusting. Nevertheless, the Warming Hole starts developing already during the first decade of the perturbation experiments and then gradually strengthens, which supports the model-observation comparison.

\section{Conclusions}

In this study, we have applied an optimal flux perturbations framework to examine how changes in surface heat and freshwater fluxes over different regions of the ocean affect the AMOC slowdown, which is motivated in part by the recent decline in Arctic sea ice exposing the ocean to more sunlight and freshwater. We have shown that anomalous fluxes over the subpolar North Atlantic have the largest impact on the AMOC on timescales from years to a decade, whereas anomalies in the Arctic ocean become dominant on multi-decadal and longer timescales. On such long timescales, the impact of surface flux anomalies over the Arctic can be twice as large as those imposed over the North Atlantic. The dominant role of Arctic surface flux anomalies for 
AMOC weakening is further confirmed by forward ocean integrations wherein we impose surface flux anomalies of the past several decades reconstructed from the available observations. Heat flux anomalies appear to be a primary factor in the AMOC weakening, with a smaller contribution from freshwater. The relatively modest contribution of present freshwater flux anomalies is confirmed by previous high-resolution ocean simulations, even though freshwater fluxes may become a more important driver of AMOC decline in the future as suggested by our climate model experiments and future climate projections ${ }^{28}$. It is also important to note that the structure of optimal surface heat and freshwater fluxes can change for higher resolution models, leading to finer structures and potentially increasing the effect of freshwater released at the ocean boundaries (including river runoff $\left.{ }^{29}\right)$.

Our complementary simulations using a global climate model, wherein we perturb sea ice radiative budget in the Arctic and induce a sea ice retreat comparable to the observed over the recent decades (in terms of spatial structure and magnitude), show a similar ocean response as the ocean-only approach. These coupled model experiments exhibit an AMOC weakening at a rate of $\sim 1 \mathrm{~Sv}$ per decade, which leads to a localized cooling in the subpolar/mid-latitude North Atlantic resembling with the observed Warming Hole.

The magnitude and pattern of SST changes that result from the modeled Arctic sea ice decline and associated surface flux anomalies are broadly consistent with those observed in the Arctic and North Atlantic over recent decades see (Fig. 2c and Fig. 6d). So is the approximate magnitude of the simulated AMOC slow-down. Therefore, our climate modelling experiments together with the 
forward ocean integrations imply that the recent Arctic sea ice decline could be a plausible cause of the suggested AMOC slow-down. (Another contribution to the observed AMOC variations may come from oceanic internal and/or wind-forced variability.)

The AMOC weakening can have important remote climate impacts, such as increased storminess over Europe ${ }^{30}$. Finally, since summer Arctic sea ice is expected to disappear before the end of the current century ${ }^{31}$, our study implies that the AMOC will continue to weaken, causing a further decrease in ocean meridional heat transport and reducing to some extent the global warming signal over the ocean locally in the North Atlantic. However, if this effect saturates, the North Atlantic will be warming at a pace significantly higher than currently observed ${ }^{11}$.

\section{References}

1. Parkinson, C. L. \& Cavalieri, D. J. Arctic sea ice variability and trends, 1979-2006. J. Geophys. Res. 113, C07003 (2008).

2. Stroeve, J. et al. Arctic sea ice extent plummets in 2007. Eos 19, 1365-1387 (2008).

3. Drijfhout, S., van Oldenborgh, G. J. \& Cimatoribus, A. Is a decline of amoc causing the warming hole above the north atlantic in observed and modeled warming patterns? J. Climate 25, 8373-8379 (2012).

4. Rahmstorf, S. et al. Exceptional twentieth-century slowdown in atlantic ocean overturning circulation. Nature Clim. Change 5, 475-480 (2015). 
5. McCarthy, G. et al. Observed interannual variability of the atlantic meridional overturning circulation at $26.5^{\circ}$ N. Geophys. Res. Lett. 39, L19609 (2012).

6. Smeed, D. A. et al. Observed decline of the atlantic meridional overturning circulation 2004 to 2012. Ocean Sci. 10, 29-38 (2014).

7. Jackson, L. C., Peterson, K. A., Roberts, C. D., \& Wood, R. A. Recent slowing of atlantic overturning circulation as a recovery from earlier strengthening. Nat. Geosci. 9, 518522 (2016).

8. Zhao, J. \& Johns, W. Wind-forced interannual variability of the atlantic meridional overturning circulation at $26.5^{\circ}$ N. J. Geophys. Res. Oceans 119, 2403-2419 (2014).

9. Buckley, M. W. \& Marshall, J. Observations, inferences, and mechanisms of the atlantic meridional overturning circulation: A review. Rev. Geophys. 54, 5-63 (2016).

10. Cheng, W., Chiang, J. C. H. \& Zhang, D. Atlantic meridional overturning circulation (amoc) in cmip5 models: Rcp and historical simulations. Clim. Dyn. 26, 7187-7197 (2013).

11. Drijfhout, S. Competition between global warming and an abrupt collapse of the amoc in earth's energy imbalance. Scientific Report 5, 14877 (2015).

12. Sutton, R. W. \& Hodson, D. L. R. Atlantic ocean forcing of north american and european summer climate. Science 309, 115-118 (2005).

13. Srokosz, M. \& Bryden, H. L. Observing the atlantic meridional overturning circulation yields a decade of inevitable surprises. Science 348, 1330 (2015). 
14. Robson, J., Hodson, D., Hawkins, E. \& Sutton, R. Atlantic overturning in decline? Nat. Geosci. 7, 2-3 (2014).

15. Deshayes, J. et al. Oceanic hindcast simulations at high resolution suggest that the atlantic moc is bistable. Geophys. Res. Lett. 40, 3069-3073 (2013).

16. Heimbach, P. et al. Timescales and regions of the sensitivity of atlantic meridional volume and heat transport: toward observing system design. Deep Sea Research Part II: Topical Studies in Oceanography 58, 1858-1879 (2011).

17. Bugnion, V., Hill, C. \& Stone, P. H. An adjoint analysis of the meridional overturning circulation in a hybrid coupled model. J. Climate 19, 3751-3767 (2006).

18. Sévellec, F. \& Fedorov, A. V. Amoc sensitivity to surface buoyancy fluxes: Stronger ocean meridional heat transport with a weaker amoc? Clim. Dyn. DOI 10.1007/s00382-015-2915-4 (2016).

19. Pillar, H. R., Heimbach, P., Johnson, H. L. \& Marshall, D. P. Dynamical attribution of recent variability in atlantic overturning. J. Climate 29, 3339-3352 (2016).

20. Madec, G., Delecluse, P., Imbard, M. \& LÃ(C)vy, C. Opa 8.1 ocean general circulation model reference manual. Tech. Rep., Institut Pierre-Simon Laplace (IPSL), France, No11, 91pp (1998).

21. Weaver, A. T., Vialard, J. \& Anderson, D. L. T. Three- and four-dimensional variational assimilation with a general circulation model of the tropical pacific ocean. part 1: formulation, internal diagnostics and consistency checks. Mon. Wea. Rev. 131, 1360-1378 (2003). 
22. Sévellec, F. \& Fedorov, A. V. The leading, interdecadal eigenmode of the atlantic meridional overturning circulation in a realistic ocean model. J. Climate 26, 2160-2183 (2013).

23. Sévellec, F. \& Fedorov, A. V. Optimal excitation of amoc decadal variability: links to the subpolar ocean. Prog. Oceanogr. 132, 287-304 (2015).

24. Yang, Q. et al. Recent increases in arctic freshwater flux affects labrador sea convection and atlantic overturning circulation. Nature Communications 7, 20525 (2016).

25. IPCC. Climate Change 2013 - The Physical Science Basis: Contribution of Working Group I to the Fifth Assessment Report of the IPCC (Cambridge: Cambridge University Press, 2013).

26. Lindsay, R., Wensnahan, M., Schweiger, A. \& Zhang, J. Evaluation of seven different atmospheric reanalysis products in the arctic. J. Climate 27, 2588-2606 (2014).

27. Hurrell, J. W. et al. The community earth system model: a framework for collaborative research. Bull. of the Amer. Meteor. Soc. 94, 1339-1360 (2013).

28. Böning, C. W., Behrens, E., Biastoch, A., Getzla, K. \& Bamber, J. L. Emerging impact of greenland meltwater on deepwater formation in the north atlantic ocean. Nat. Geosci. 9, 523527 (2016).

29. Peterson, B. J. et al. Increasing river discharge to the arctic ocean. Science 298, 2171-2173 (2002)

30. Jackson, L. C. et al. Global and european climate impacts of a slowdown of the amoc in a high resolution gcm. Clim. Dyn. 45, 3299-3316 (2015). 
31. Boé, J., Hall, A. \& Qiu, X. September sea-ice cover in the arctic ocean projected to vanish by 2100. Nat. Geosci. 2, 341-343 (2009).

32. Cavalieri, D., Parkinson, C., Gloersen, P. \& Zwally, H. J. Sea ice concentrations from nimbus7 smmr and dmsp ssm/i-ssmis passive microwave data. Tech. Rep., Boulder, Colorado USA: NASA DAAC at the National Snow and Ice Data Center (1996).

33. Frajka-Williams, E. et al. Compensation between meridional flow components of the atlantic moc at $26^{\circ}$ n. Ocean Sci. 12, 481-496 (2016).

34. Muir, L. C. \& Fedorov, A. V. How the amoc affects ocean temperatures on decadal to centennial timescales: the north atlantic versus an interhemispheric seesaw. Clim. Dyn. 45, 151-160 (2015).

35. Talley, L. D., Reid, J. L. \& Robbins, P. E. Data-based meridional overturning streamfunctions for the global ocean. J. Climate 16, 3213-3226 (2003).

36. Ganachaud, A. \& Wunsch, C. Improved estimates of global ocean circulation, heat transport and mixing from hydrographic data. Nature 408, 453-457 (2000).

37. Dee, D. P. et al. The era-interim reanalysis: configuration and performance of the data assimilation system. Quarterly Journal of the Royal Meteorological Society 137, 553-597 (2011).

38. Lindsay, R. \& Schweiger, A. Arctic sea ice thickness loss determined using subsurface, aircraft, and satellite observations. The Cryosphere 9, 269-283 (2015).

39. Shields, C. et al. The low-resolution ccsm4. J. Climate 25, 3993-4014 (2012). 
40. Eisenman, I. \& Wettlaufer, J. S. Nonlinear threshold behavior during the loss of arctic sea ice. Proc. Nat. Acad. Sci. U.S.A. 106, 28-32 (2009).

41. Briegleb, P. \& Light, B. A delta-eddington multiple scattering parameterization for solar radiation in the sea ice component of the community climate system model. Tech. Rep., NCAR Tech. Note NCAR/TN-472+STR, National Center for Atmospheric Research (2007).

42. Burls, N. J. \& Fedorov, A. V. What controls the mean east-west sea surface temperature gradient in the equatorial pacific: the role of cloud albedo. J. Climate 27, 2757-2778 (2014).

Acknowledgements This research was supported by grant to FS from the Natural and Environmental Research Council UK (SMURPHS, NE/N005767/1) and by grants to AVF from DOE Office of Science (DE-SC0016538) and NOAA (NA14OAR4310277). Support from the Yale University High Performance Computing facilities is also acknowledged. We thank Brian Dobbins for his help with setting up numerical experiments and three anonymous reviewers for their constructive comments.

Competing Interests The authors declare no competing financial interests.

Author Contribution All three authors contributed equally to the experimental design, the data analysis, and the writing of the manuscript.

Correspondence Correspondence and requests for materials should be addressed to F. Sévellec (email: f.sevellec@soton.ac.uk). 


\section{Methods}

Sea ice extent. Sea ice concentration is derived from Nimbus-7 SMMR and DMSP SSM/I-SSMIS Passive Microwave Data, provided by the National Snow and Ice Data Center $^{32}$ for the period 19792014. We use annual mean values since they are representative of the extent of open water in the Arctic. To characterize sea ice cover we use four variables - ocean areas with sea ice concentration greater than $85 \%, 50 \%$ and $15 \%$ and total area of sea ice (Fig. 1), all of which show a loss of sea ice since 1979 (Fig. 1c). Typically, sea ice extent is defined as the area of the ocean with ice concentration above $15 \%$. Total area of sea ice is defined as the net area of the ocean fully covered with ice, which can be computed by integrating ice fraction over the entire region of the ocean where ice forms.

AMOC observational records. We use data from the RAPID monitoring system ${ }^{5}$, operating along $26.5^{\circ} \mathrm{N}$ since 2004 . We apply a 4-year running mean to smooth the data and compute a linear trend (Fig. 2a) on the order of 4 Sv per decade consistent with previous analyses ${ }^{6}$. The mean AMOC strength ${ }^{33}$ estimated from RAPID observations and atmospheric wind products (which provide Ekman flow) is $18.4 \pm 1.3 \mathrm{~Sv}$ for $2004-2009$ and $15.5 \pm 1.9 \mathrm{~Sv}$ for 2009-2014. Thus, the AMOC weakened by about $20 \%$ since 2004 , even though some, or all of this decline can be due to natural decadal variability ${ }^{9}$.

We also generate a longer, proxy AMOC record (Fig. 2b) following earlier studies ${ }^{3,4}$ that linked changes in the AMOC intensity and temperature trends in the subpolar North Atlantic relative to the northern hemisphere (Fig. S1a). Accordingly, the AMOC proxy ${ }^{4}$ is defined as the dif- 
ference between mean surface air temperatures in the region between $50^{\circ} \mathrm{N}$ to $60^{\circ} \mathrm{N}$ (from $10^{\circ} \mathrm{W}$ to $50^{\circ} \mathrm{W}$ ) and the northern hemisphere (Fig. S1b). This proxy record is scaled using a multi-model mean sensitivity of the subpolar North Atlantic sea surface temperature ${ }^{34}$ of $0.3^{\circ} \mathrm{C}$ per $1 \mathrm{~Sv}$ valid on multi-decadal to centennial timescales. We again apply a 4-year running mean to filter out interannual AMOC variability controlled largely by the winds ${ }^{8}$.

Computing optimal surface fluxes. The AMOC sensitivity to heat and freshwater fluxes is assessed by computing Linear Optimal Perturbations (LOPs) in ocean surface fluxes. This framework ${ }^{18}$ yields normalized optimal fluxes that affect the AMOC the most. The computations use the tangent linear and adjoint versions of the NEMO ocean model ${ }^{20}$ in its ORCA2 configuration $\left(2^{\circ} \times 2^{\circ}\right.$ horizontal resolution and 31 vertical levels). Although this configuration is relatively coarse, the general approach represents state-of-the-art in adjoint ocean modeling ${ }^{16,18,19}$. In addition, this resolution allows filtering out baroclinic instability that would contaminate the solutions otherwise. In the full nonlinear model the mean AMOC intensity reaches 14 Sv (Fig. S2), which lies within the observational estimates $^{35}$ of $18 \pm 5 \mathrm{~Sv}$ and is generally in line with the more recent RAPID's data ${ }^{5}$ Consistent with the volume transport, the model Atlantic meridional heat transport is $0.8 \mathrm{PW}$ at $25^{\circ} \mathrm{N}$ (Fig. S2), slightly lower than 1.3 PW estimated from inverse calculations and hydrographic sections $^{36}$ at $26.5^{\circ} \mathrm{N}$.

We start with an expression for an ocean state anomaly induced by steady surface flux perturbation: 


$$
|\boldsymbol{u}(\tau)\rangle=\int_{0}^{\tau} d s \mathbf{M}(s) \mathbf{B}_{\mathrm{hf} / \mathrm{fw}}\left|\boldsymbol{f}_{\mathrm{hf} / \mathrm{fw}}\right\rangle
$$

where $s$ is a time variable, $|\boldsymbol{u}(\tau)\rangle$ describes the ocean state anomaly at time $\tau, \tau$ is the duration of the imposed heat and freshwater flux anomalies $\left(\left|\boldsymbol{f}_{\mathrm{hf} / \mathrm{fw}}\right\rangle\right.$, respectively), and $\mathbf{B}_{\mathrm{hf} / \mathrm{fw}}$ are linearized heat and freshwater flux operators, respectively. $\mathbf{M}(s)$ is the propagator of ocean dynamics over the duration $s$. It is based on the linearization of the GCM's equations of motion around the mean climatological state of the model ocean. The propagator connects ocean state anomalies at time zero and $\tau$.

The validity of the linear assumption is related to the magnitude of the imposed surface flux anomalies (rather than their duration) relative to the magnitude of typical mean surface fluxes in the Arctic. In this study we use freshwater and heat flux anomalies (Fig. 5) an order of magnitude smaller than their climatological values.

The optimality is defined through a cost function (denoted by $\langle\boldsymbol{F}|$ ). We choose to measure the AMOC intensity as the zonally-averaged meridional volume transport at $50^{\circ} \mathrm{N}$ and $1,500 \mathrm{~m}$ depth. This location allows us to measure changes in AMOC intensity in a linear framework, as it corresponds to the local maximum of the mean streamfunction in the subpolar region (Fig. S2a). This region has been demonstrated in previous studies ${ }^{22}$ to exhibit strongest variability between 40 and $60^{\circ} \mathrm{N}$ in this particular ocean model.

To find optimal heat and freshwater fluxes that modify the AMOC intensity the most under 
a normalization constraint on the flux amplitude, we introduce a Lagrangian function:

$$
\mathcal{L}\left(\left|\boldsymbol{f}_{\mathrm{hf} / \mathrm{fw}}\right\rangle, \gamma\right)=\langle\boldsymbol{F} \mid \boldsymbol{u}(\tau)\rangle-\gamma\left(\left\langle\boldsymbol{f}_{\mathrm{hf} / \mathrm{fw}}|\mathbf{S}| \boldsymbol{f}_{\mathrm{hf} / \mathrm{fw}}\right\rangle-\epsilon^{2}\right)
$$

where $\gamma$ is a Lagrange multiplier, $\mathbf{S}$ is a normalization operator, and $\epsilon$ is a parameter associated with the normalization constraint:

$$
\left\langle\boldsymbol{f}_{\mathrm{hf} / \mathrm{fw}}|\mathbf{S}| \boldsymbol{f}_{\mathrm{hf} / \mathrm{fw}}\right\rangle=\frac{\iint d \sigma f_{\mathrm{hf} / \mathrm{fw}}^{2}}{\iint d \sigma}=\epsilon^{2},
$$

where $d \sigma$ is a unit surface and $f_{\mathrm{hf} / \mathrm{fw}}$ is surface heat and freshwater fluxes, respectively. $\epsilon$ gives the root mean square amplitude of the fluxes over the entire ocean. We set $\epsilon=1 \mathrm{~W} \mathrm{~m}^{-2}$ or $1 \mathrm{~cm} \mathrm{yr}^{-1}$. Our goal is to maximize the cost function subject to this normalization constraint.

From expression (2) and the general optimization condition $d \mathcal{L}=0$, optimal flux perturbations for the duration $\tau$ are computed as

$$
\left|\boldsymbol{f}_{\mathrm{hf} / \mathrm{fw}}^{\tau}\right\rangle= \pm \frac{1}{\gamma} \int_{0}^{\tau} d s \mathbf{S}^{-1} \mathbf{B}_{\mathrm{hf} / \mathrm{fw}}^{\dagger} \mathbf{M}^{\dagger}(s)|\boldsymbol{F}\rangle
$$

where $\dagger$ represents an adjoint (defined through an Euclidean scalar product) and

$$
\gamma^{2}=\iint_{0}^{\tau} d s d s^{\prime}\left\langle\boldsymbol{F}\left|\mathbf{M}(s) \mathbf{B}_{\mathrm{hf} / \mathrm{fw}} \mathbf{S}^{-1} \mathbf{B}_{\mathrm{hf} / \mathrm{fw}}^{\dagger} \mathbf{M}^{\dagger}\left(s^{\prime}\right)\right| \boldsymbol{F}\right\rangle
$$

Consequently, $\gamma$ gives the optimal impact of the normalized flux anomalies.

These last expressions demonstrate that the optimal flux perturbations $\left(\left|\boldsymbol{f}_{\mathrm{hf} / \mathrm{fw}}^{\tau}\right\rangle\right)$, as well as their impact $(\gamma)$, can be computed through the propagation of the cost function $(\langle\boldsymbol{F}|)$ by the adjoint model $\left(\mathbf{M}^{\dagger}\right)$. For further details of the approach see refs. Sévellec and Fedorov (2015 and $2016)^{18,23}$. 
Estimating decadal anomalies in surface heat and freshwater fluxes. Available data on recent changes in surface heat and freshwater fluxes have large uncertainties in the Arctic ocean ${ }^{26}$. These uncertainties are related to the limited observational network and deficiencies of atmospheric reanalyses. Consequently, we use reconstructed flux anomalies, rather than directly measured. When integrating the forward ocean model, we assume that these surface flux anomalies do not change over the 100-yr duration of the integrations.

For heat flux anomalies we compute the difference in surface heat fluxes between 1988-1994 and 2004-2015 from ERA-INTERIM ${ }^{37}$. These heat fluxes are modified by seasonal changes in sea ice cover (from the same dataset) to reflect the amount of heat that can actually reach the ocean below sea ice. Also, we add a uniform flux (a constant) over the global ocean to have a net downward flux of $+0.55 \mathrm{~W} \mathrm{~m}^{-2}$ consistent with the estimated ocean warming signal during the recent decades ${ }^{25}$.

For freshwater fluxes we combine three main sources of freshwater anomalies: Arctic sea ice melting, Greenland ice sheet melting and changes in the atmospheric hydrological cycle. Sea ice melting is accounted for by adding a freshwater flux based on the total loss of Arctic sea ice ${ }^{38}$ volume estimated for 1995-2015. This corresponds to a uniform flux of $-5.2 \mathrm{~cm} \mathrm{yr}^{-1}$ (using $900 \mathrm{~kg} \mathrm{~m}^{-3}$ for sea ice density) over the Arctic ocean (corresponding to a net volume flux of $\left.0.8 \times 10^{12} \mathrm{~m}^{3} \mathrm{yr}^{-1}\right)$. The $1988-2014$ rate of mass loss in the Greenland ice sheet ${ }^{24}(3,000 \mathrm{Gt}$ in $12.5 \mathrm{yr}$ ) is converted into a uniform freshwater flux of $-1.5 \mathrm{~cm} \mathrm{yr}^{-1}$, also restricted to the Arctic ocean (corresponding to a net flux of $0.2 \times 10^{12} \mathrm{~m}^{3} \mathrm{yr}^{-1}$ ). Note that this use of uniform fluxes enhances their impacts on the AMOC, since it increases their projection onto the almost uniform 


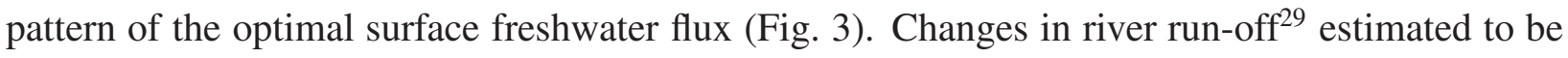

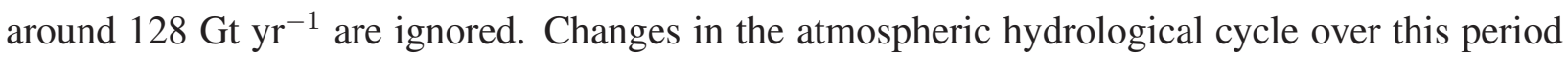
due to global warming are approximated following the IPCC as a $10 \%$ increase $^{25}$ in the mean evaporation-minus-precipitation field over the global ocean (given by a 1988-2015 mean field from ERA-INTERIM). The resultant freshwater flux in the Arctic (Fig. 5b), to be imposed in the forward linear model, is spatially varying, but these variations are relatively small.

Replicating Arctic sea ice decline in a comprehensive climate model. The coupled climate model employed in this study is the Community Earth System Model (CESM) ${ }^{27}$ developed by the National Center for Atmospheric Research. We use CESM version 1.0.4 (T31gx3v7) with a T31 spectral dynamical core for the atmospheric and land components (horizontal grid of $3.75^{\circ} \times 3.75^{\circ}$ ) with 26 atmospheric layers in the vertical. The ocean and ice components employ a nominal $3^{\circ}$ irregular horizontal grid that increases to $1^{\circ}$ near the equator and has 60 ocean layers in the vertical $^{39}$. The model horizontal resolution becomes significantly finer toward Greenland and the Arctic to better resolve ocean topography in high latitudes.

As the exact driving mechanisms of the Arctic sea ice decline are still debated ${ }^{40}$, to assess its impacts on the AMOC we have adopted two independent approaches that reproduce a realistic Arctic sea ice loss of the past several decades (in terms of spatial structure and magnitude) by changing the radiation balance of sea ice. In the first approach we reduce the emissivity of sea ice and overlying snow, which decreases outgoing longwave radiation flux (LW). In the second approach we reduce the net reflectivity (albedo) of sea ice and snow which increases absorbed shortwave radiation (SW). Perturbing sea ice radiative properties is the only modification from the 
control experiment. After conducting several sensitivity experiments we arrive at two simulations most closely replicating the observed seasonal cycle of the Arctic sea ice decline. In the LW experiment, we reduce the emissivity of snow and ice by a factor of $10^{-4}$. In the SW experiment, we modify the optical properties of snow, bare sea ice and ponded ice in the Delta-Eddington solar radiation treatment ${ }^{41}$ within the model's ice component. Specifically, for snow, we reduce the single scattering albedo (the probability that a single event results in scattering) by $10 \%$ for all spectral bands. For bare ice and ponded ice, we adjust their optical properties by changing the standard deviation parameters $\left(\mathrm{R}_{\mathrm{ice}}\right.$ and $\left.\mathrm{R}_{\mathrm{pnd}}\right)$ from 0 to -2 . As no modifications are applied over open water, the main result of these modifications is sea ice contraction at the ice margins.

The experiments start from a CESM quasi-equilibrium preindustrial control simulation ${ }^{42}$ and are run for 200 years after a perturbation to sea ice radiative balance is imposed; averages for the last 50 years are used for analysis in Figs. 6a-d, Fig. S6, and Fig. S7. Both SW and LW experiments simulate an Arctic sea ice decline very similar to the observed between the periods 1979-1988 and 2005-2014 according to the data from the National Snow and Ice Data Center (Fig. 6c), even though direct comparison is somewhat limited because, unlike the quasi-equilibrated solutions, the real ocean is still adjusting. The close similarity between the two experiments (Fig. 6, Fig. S6-8) demonstrates that our results from the coupled model are robust and do not depend on a particular method used to modify sea ice radiation balance.

Code availability NEMO code is available at http://www. nemo-ocean. eu and CESM at http: //www. cesm. ucar.edu/. Specific configurations can be provided upon request. 
Data availability The datasets generated and analysed during the current study are available from the corresponding author on request. 
Figure 1 Changes in Arctic sea ice since 1979. (a,b) Annual mean sea ice concentration for two periods: 1979-1988 and 2005-2014. The blue, purple and red contours indicate concentration of $85 \%, 50 \%$, and $15 \%$, respectively. The $15 \%$ contour is typically chosen as the formal boundary of sea ice. (c) Changes in the areas with ice concentration above $15 \%$ (red line), 50\% (purple) and 85\% (blue), and changes in sea ice total area (black). The last variable refers to the net area of the ocean covered with ice (i.e., ice fraction integrated spatially over the northern high latitudes). It has decreased by $\sim 20 \%$ over the last 35 years. Sea ice concentration is derived from the satellite-based Passive Microwave data and provided by the National Snow and Ice Data Center ${ }^{32}$, see Methods.

Figure 2 Observational evidence of the AMOC slow-down. (a) The strength of the Atlantic Meridional Overturning Circulation at $26.5^{\circ} \mathrm{N}$ from RAPID measurements ${ }^{5}$ showing a weakening of this circulation over the past decade ${ }^{6}$. Debate continues on whether this represents a secular trend or natural variability. (b) An AMOC index defined as the difference in surface air temperatures between the subpolar North Atlantic $\left(50^{\circ} \mathrm{N}\right.$ to $60^{\circ} \mathrm{N}$ and $10^{\circ} \mathrm{W}$ to $50^{\circ} \mathrm{W}$ ) and the northern hemisphere ${ }^{4}$. This index indicates a negative trend in the AMOC intensity over the last century. To convert temperature into AMOC variations we use a scaling ${ }^{34}$ of $0.3^{\circ} \mathrm{C}$ per Sv. A 4-year running mean was applied and the mean removed. This analysis suggests that the recent AMOC slow-down is part of a more gradual AMOC decline of about 0.2 Sv per decade during the last century. (c) A map of local surface air temperature trends over the ocean for 1900 - 2015 in the Northern high latitudes. The subpolar North Atlantic shows a weaker warming with a region of negative 
trend south of Greenland often referred to as the Warming Hole and conjectured to be caused by the AMOC slow-down ${ }^{3,4}$. NASA GISS temperatures were used; gray indicates insufficient data.

Figure 3 Optimal surface fluxes to modify the AMOC. The plot shows spatial patterns in ocean fluxes of (a-d) heat and (e-h) freshwater that reduce the AMOC intensity the most for several different durations of the imposed flux perturbations: $10,20,50$, and 100 years. The corresponding AMOC reduction (in Sv) is provided above each panel. The patterns were computed using the adjoint ocean GCM (Methods). For mutual comparison, optimal heat and freshwater fluxes have been normalized to have root mean square amplitudes over the entire ocean of $1 \mathrm{~W} \mathrm{~m}^{-2}$ and $1 \mathrm{~cm} \mathrm{yr}^{-1}$, respectively. Solid black contours indicate zero values. The purple line follows $50^{\circ} \mathrm{N}$ - the latitude where the AMOC intensity is evaluated.

Figure 4 AMOC sensitivity to optimal heat and freshwater fluxes. The graphs shows the reduction of the AMOC intensity induced by optimal fluxes in $(a, c)$ heat and $(b, d)$ freshwater of different durations, including the contribution of different geographical regions. The corresponding optimal patterns are displayed in Fig. 3, also see Methods. In (a) and (b) model results are shown as small crosses connected with a cubic spline interpolation. The total sensitivity (GLOB, black line) has been split into separate sensitivities to fluxes applied over particular geographical regions: the Arctic (ARCT, red line), the North Atlantic (NATL, blue line), and the rest of the ocean (ROTO, purple line) as shown in the insert in 
panel (c). The relative contributions of the three regions (NATL, ARCT, and ROTO) to the total sensitivity are shown in panels (c) and (d).

Figure 5 Estimated decadal changes in ocean surface fluxes and the model AMOC response. $(a, b)$ Anomalies in surface fluxes of $(a)$ heat and $(b)$ freshwater reconstructed for the period 2004-2015 relative to $1988-1994$, see Methods. Anomalies in heat fluxes are based on the ERA-INTERIM data ${ }^{37}$ modified here to allow for a global mean downward oceanic heat flux of $+0.55 \mathrm{~W} \mathrm{~m}^{-2}$. Anomalies in freshwater fluxes incorporate changes in the atmospheric hydrological cycle and the contributions from the melting Greenland ice sheet and Arctic sea ice (Fig. 1C), both uniformly distributed over the Arctic ocean. The resultant Arctic freshwater flux anomaly is spatially varying, but these variations are relatively small. These reconstructions indicate that the Arctic ocean has experienced a net warming of $8.2 \mathrm{~W} \mathrm{~m}^{-2}$ and a freshening of $8.7 \mathrm{~cm} \mathrm{yr}^{-1}$. (c,d) The model AMOC response to the reconstructed flux anomalies, maintained for 100 years, is presented in terms of (c) oceanic meridional volume transport at $50^{\circ} \mathrm{N}$ and (d) heat transport (MHT) at $25^{\circ} \mathrm{N}$. Model results, obtained from the forward ocean GCM, are shown as small crosses connected by a cubic spline interpolation. The AMOC total response to the reconstructed fluxes (GLOB, black line) is again split into components due to three geographical regions: the Arctic (ARCT, red line), the North Atlantic (NATL, blue line) and the rest of the ocean (ROTO, purple line). 
Figure 6 Arctic sea ice retreat and its impacts simulated by a climate GCM. The effects of sea ice decline are isolated within two experiments perturbing sea ice radiation balance: LW (reducing longwave emissivity of sea ice) and SW (reducing shortwave reflectivity). Both perturbation experiments start from the same preindustrial control (CTL). (a,b) Annual-mean sea ice concentration (in \%) in the CTL and LW experiments, and (d) SST anomalies in the latter simulation. The blue, purple and red contours mark $85 \%, 50 \%$, and $15 \%$ sea ice concentrations; SST contour intervals are $0.5^{\circ} \mathrm{C}$. (c) Relative decline (in \%) of sea ice total area for different months of the year in the observations (black line) and LW (blue) and SW (red) experiments. The observations reflect the difference between 2005-2014 and 1979-1988. Model output was averaged within the last 50 years of the CTL and within years 151-200 for the LW and SW experiments. (e,f) Total area of Arctic sea ice (in $10^{6} \mathrm{~km}^{2}$ ) and the AMOC volume transport (Sv) at $50^{\circ} \mathrm{N}$ as a function of time in the CTL (purple), LW (blue) and SW (red) experiments. Perturbations to sea ice radiative balance are applied instantaneously at time zero and then maintained for the duration of each experiment (Methods). Note the multi-decadal timescale of AMOC adjustment. 
Arctic sea ice decline weakens the Atlantic Meridional

$$
\text { Overturning Circulation }
$$

Florian Sévellec, Alexey V. Fedorov, and Wei liu

Figures 


\section{List of Figures}

1 Changes in Arctic sea ice since 1979. (a,b) Annual mean sea ice concentration for two periods: 1979-1988 and 2005-2014. The blue, purple and red contours indicate concentration of $85 \%, 50 \%$, and $15 \%$, respectively. The $15 \%$ contour is typically chosen as the formal boundary of sea ice. (c) Changes in the areas with ice concentration above 15\% (red line), 50\% (purple) and 85\% (blue), and changes in sea ice total area (black). The last variable refers to the net area of the ocean covered with ice (i.e., ice fraction integrated spatially over the northern high latitudes). It has decreased by $\sim 20 \%$ over the last 35 years. Sea ice concentration is derived from the satellite-based Passive Microwave data and provided by the National Snow and Ice Data Center ${ }^{32}$, see Methods. . . . . . . . . . . . . . . . . . . . . . . .

2 Observational evidence of the AMOC slow-down. (a) The strength of the Atlantic Meridional Overturning Circulation at $26.5^{\circ} \mathrm{N}$ from RAPID measurements ${ }^{5}$ showing a weakening of this circulation over the past decade ${ }^{6}$. Debate continues on whether this represents a secular trend or natural variability. (b) An AMOC index defined as the difference in surface air temperatures between the subpolar North Atlantic $\left(50^{\circ} \mathrm{N}\right.$ to $60^{\circ} \mathrm{N}$ and $10^{\circ} \mathrm{W}$ to $50^{\circ} \mathrm{W}$ ) and the northern hemisphere ${ }^{4}$. This index indicates a negative trend in the $\mathrm{AMOC}$ intensity over the last century. To convert temperature into AMOC variations we use a scaling ${ }^{34}$ of $0.3^{\circ} \mathrm{C}$ per Sv. A 4-year running mean was applied and the mean removed. This analysis suggests that the recent AMOC slow-down is part of a more gradual AMOC decline of about $0.2 \mathrm{~Sv}$ per decade during the last century. (c) A map of local surface air temperature trends over the ocean for 1900 - 2015 in the Northern high latitudes. The subpolar North Atlantic shows a weaker warming with a region of negative trend south of Greenland often referred to as the Warming Hole and conjectured to be caused by the AMOC slow-down ${ }^{3,4}$. NASA GISS temperatures were used; gray indicates insufficient data. . . . . . . . . . . . . . . . .

3 Optimal surface fluxes to modify the AMOC. The plot shows spatial patterns in ocean fluxes of $(\mathrm{a}-\mathrm{d})$ heat and $(\mathrm{e}-\mathrm{h})$ freshwater that reduce the AMOC intensity the most for several different durations of the imposed flux perturbations: 10, 20, 50, and 100 years. The corresponding AMOC reduction (in $\mathrm{Sv}$ ) is provided above each panel. The patterns were computed using the adjoint ocean GCM (Methods). For mutual comparison, optimal heat and freshwater fluxes have been normalized to have root mean square amplitudes over the entire ocean of $1 \mathrm{~W} \mathrm{~m}^{-2}$ and $1 \mathrm{~cm} \mathrm{yr}^{-1}$, respectively. Solid black contours indicate zero values. The purple line follows $50^{\circ} \mathrm{N}$ - the latitude where the AMOC intensity is evaluated. 
4 AMOC sensitivity to optimal heat and freshwater fluxes. The graphs shows the reduction of the AMOC intensity induced by optimal fluxes in (a,c) heat and $(b, d)$ freshwater of different durations, including the contribution of different geographical regions. The corresponding optimal patterns are displayed in Fig. 3, also see Methods. In (a) and (b) model results are shown as small crosses connected with a cubic spline interpolation. The total sensitivity (GLOB, black line) has been split into separate sensitivities to fluxes applied over particular geographical regions: the Arctic (ARCT, red line), the North Atlantic (NATL, blue line), and the rest of the ocean (ROTO, purple line) as shown in the insert in panel (c). The relative contributions of the three regions (NATL, ARCT, and ROTO) to the total sensitivity are shown in panels (c)

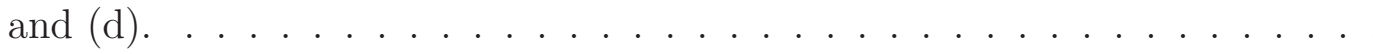

5 Estimated decadal changes in ocean surface fluxes and the model AMOC response. (a,b) Anomalies in surface fluxes of (a) heat and (b) freshwater reconstructed for the period 2004-2015 relative to 1988-1994, see Methods. Anomalies in heat fluxes are based on the ERA-INTERIM data ${ }^{37}$ modified here to allow for a global mean downward oceanic heat flux of $+0.55 \mathrm{~W} \mathrm{~m}^{-2}$. Anomalies in freshwater fluxes incorporate changes in the atmospheric hydrological cycle and the contributions from the melting Greenland ice sheet and Arctic sea ice (Fig. 1c), both uniformly distributed over the Arctic ocean. The resultant Arctic freshwater flux anomaly is spatially varying, but these variations are relatively small. These reconstructions indicate that the Arctic ocean has experienced a net warming of $8.2 \mathrm{~W} \mathrm{~m}^{-2}$ and a freshening of $8.7 \mathrm{~cm} \mathrm{yr}^{-1}$. (c,d) The model AMOC response to the reconstructed flux anomalies, maintained for 100 years, is presented in terms of (c) oceanic meridional volume transport at $50^{\circ} \mathrm{N}$ and (d) heat transport $(\mathrm{MHT})$ at $25^{\circ} \mathrm{N}$. Model results, obtained from the forward ocean GCM, are shown as small crosses connected by a cubic spline interpolation. The AMOC total response to the reconstructed fluxes (GLOB, black line) is again split into components due to three geographical regions: the Arctic (ARCT, red line), the North Atlantic (NATL, blue line) and the rest of the ocean (ROTO, purple line $\ldots \ldots \ldots \ldots \ldots \ldots \ldots$ 
6 Arctic sea ice retreat and its impacts simulated by a climate GCM. The effects of sea ice decline are isolated within two experiments perturbing sea ice radiation balance: LW (reducing longwave emissivity of sea ice) and SW (reducing shortwave reflectivity). Both perturbation experiments start from the same preindustrial control (CTL). (a,b) Annual-mean sea ice concentration (in \%) in the CTL and LW experiments, and (d) SST anomalies in the latter simulation. The blue, purple and red contours mark $85 \%, 50 \%$, and $15 \%$ sea ice concentrations; SST contour intervals are $0.5^{\circ} \mathrm{C}$. (c) Relative decline (in \%) of sea ice total area for different months of the year in the observations (black line) and LW (blue) and SW (red) experiments. The observations reflect the difference between 2005-2014 and 1979-1988. Model output was averaged within the last 50 years of the CTL and within years 151-200 for the LW and SW experiments. (e,f) Total area of Arctic sea ice (in $10^{6} \mathrm{~km}^{2}$ ) and the AMOC volume transport $(\mathrm{Sv})$ at $50^{\circ} \mathrm{N}$ as a function of time in the CTL (purple), LW (blue) and SW (red) experiments. Perturbations to sea ice radiative balance are applied instantaneously at time zero and then maintained for the duration of each experiment (Methods). Note the multi-decadal timescale of AMOC adjustment. . . . . . . . . . . . . . . . 


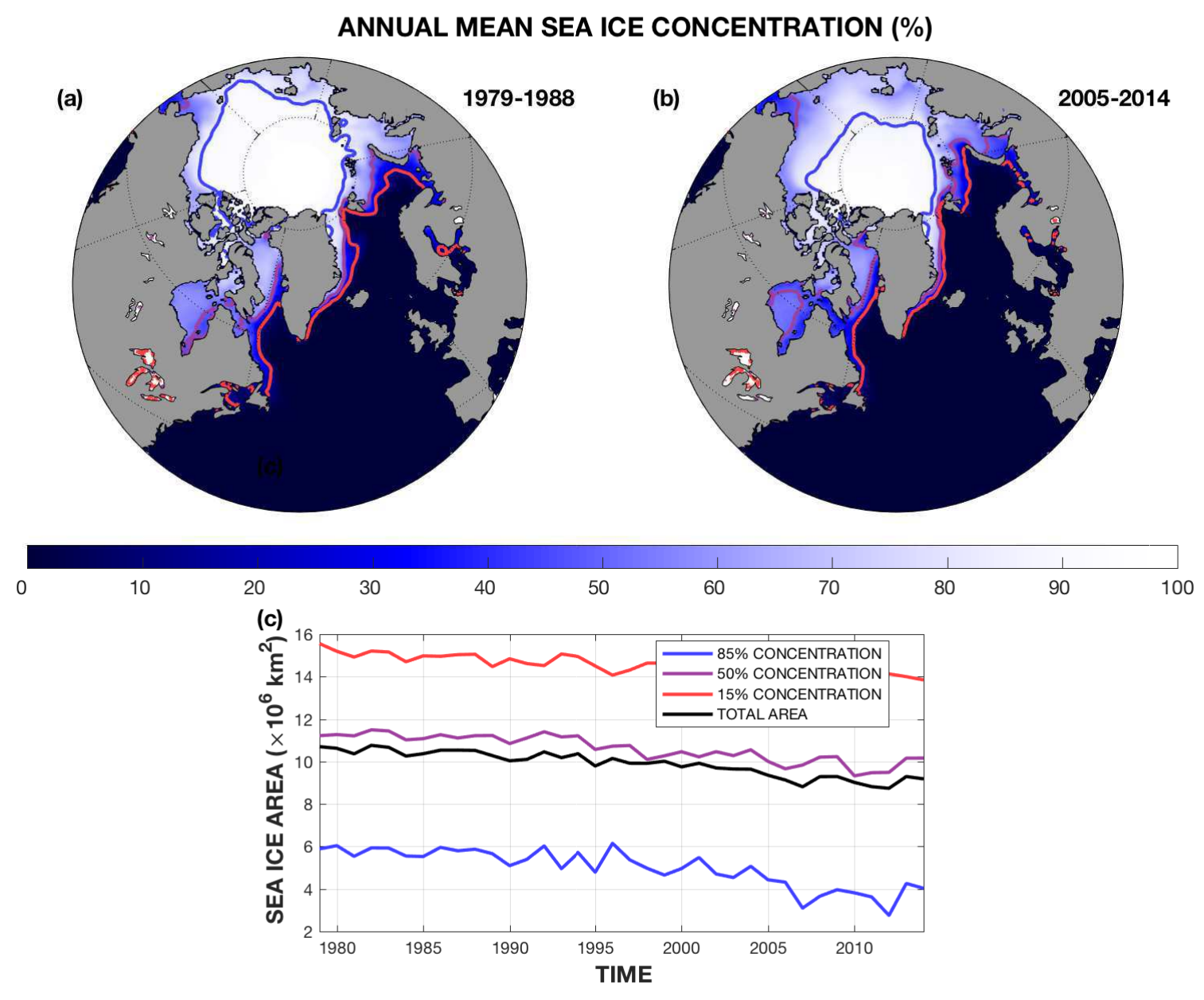

Figure 1: Changes in Arctic sea ice since 1979. (a,b) Annual mean sea ice concentration for two periods: 1979-1988 and 2005-2014. The blue, purple and red contours indicate concentration of $85 \%, 50 \%$, and $15 \%$, respectively. The $15 \%$ contour is typically chosen as the formal boundary of sea ice. (c) Changes in the areas with ice concentration above $15 \%$ (red line), $50 \%$ (purple) and $85 \%$ (blue), and changes in sea ice total area (black). The last variable refers to the net area of the ocean covered with ice (i.e., ice fraction integrated spatially over the northern high latitudes). It has decreased by $\sim 20 \%$ over the last 35 years. Sea ice concentration is derived from the satellite-based Passive Microwave data and provided by the National Snow and Ice Data Center ${ }^{32}$, see Methods. 

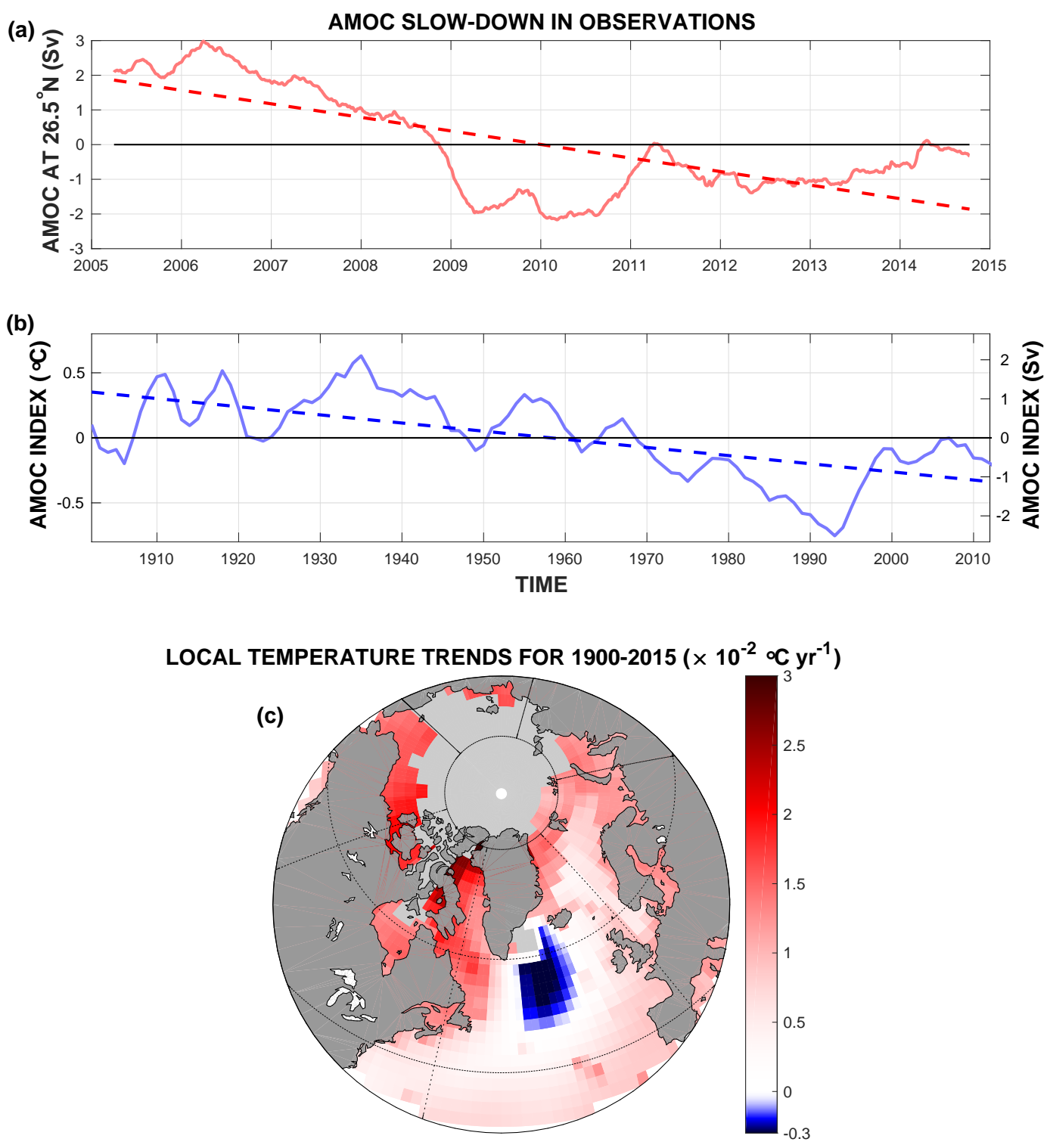

Figure 2: Observational evidence of the AMOC slow-down. (a) The strength of the Atlantic Meridional Overturning Circulation at $26.5^{\circ} \mathrm{N}$ from RAPID measurements ${ }^{5}$ showing a weakening of this circulation over the past decade ${ }^{6}$. Debate continues on whether this represents a secular trend or natural variability. (b) An AMOC index defined as the difference in surface air temperatures between the subpolar North Atlantic $\left(50^{\circ} \mathrm{N}\right.$ to $60^{\circ} \mathrm{N}$ and $10^{\circ} \mathrm{W}$ to $\left.50^{\circ} \mathrm{W}\right)$ and the northern hemisphere ${ }^{4}$. This index indicates a negative trend in the AMOC intensity over the last century. To convert temperature into AMOC variations we use a scaling ${ }^{34}$ of $0.3^{\circ} \mathrm{C}$ per Sv. A 4-year running mean was applied and the mean removed. This analysis suggests that the recent AMOC slow-down is part of a more gradual AMOC decline of about $0.2 \mathrm{~Sv}$ per decade during the last century. (c) A map of local surface air temperature trends over the ocean for 1900 2015 in the Northern high latitudes. The subpolar North Atlantic shows a weaker warming with a region of negative trend south of Greenland often referred to as the Warming Hole and conjectured to be caused by the AMOC slow-down ${ }^{3,4}$. NASA GISS temperatures were used; gray indicates insufficient data. 

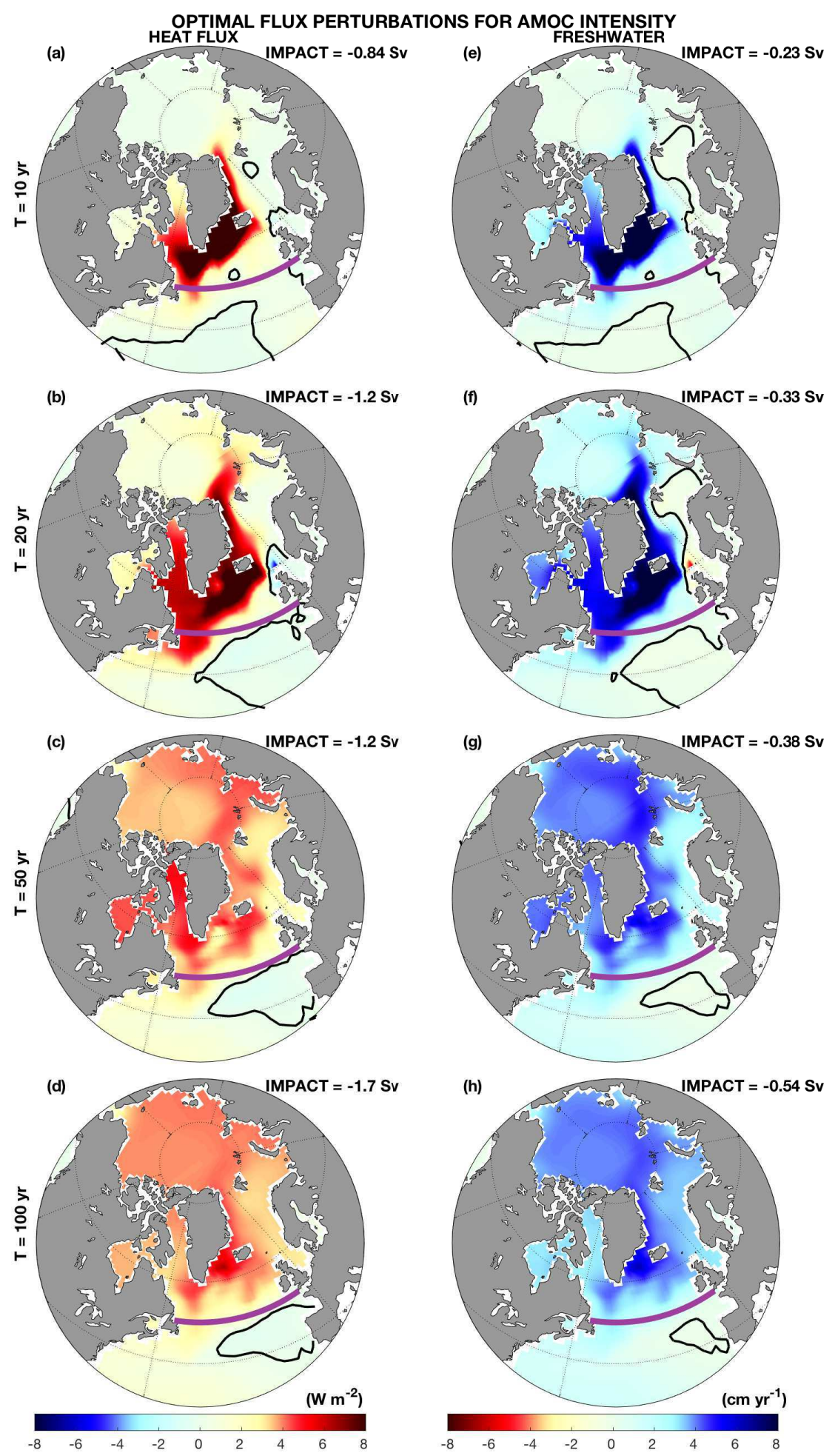

Figure 3: Optimal surface fluxes to modify the AMOC. The plot shows spatial patterns in ocean fluxes of (a-d) heat and (e-h) freshwater that reduce the AMOC intensity the most for several different durations of the imposed flux perturbations: 10, 20, 50, and 100 years. The corresponding AMOC reduction (in $\mathrm{Sv}$ ) is provided above each panel. The patterns were computed using the adjoint ocean GCM (Methods). For mutual comparison, optimal heat and freshwater fluxes have been normalized to have root mean square amplitudes over the entire ocean of $1 \mathrm{~W} \mathrm{~m}^{-2}$ and $1 \mathrm{~cm} \mathrm{yr}^{-1}$, respectively. Solid black contours indicate zero values. The purple line follows $50^{\circ} \mathrm{N}-$ the latitude where the AMOC intensity is evaluated. 

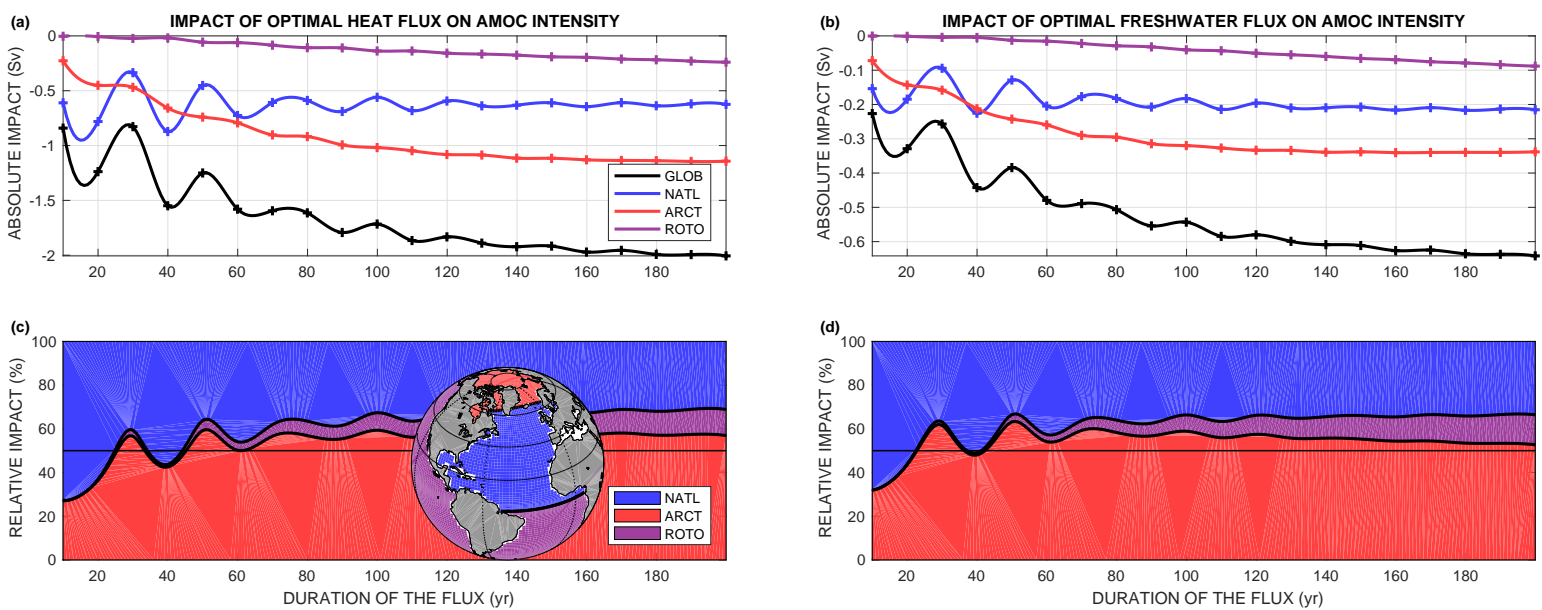

FIgURE 4: AMOC sensitivity to optimal heat and freshwater fluxes. The graphs shows the reduction of the AMOC intensity induced by optimal fluxes in (a,c) heat and (b,d) freshwater of different durations, including the contribution of different geographical regions. The corresponding optimal patterns are displayed in Fig. 3, also see Methods. In (a) and (b) model results are shown as small crosses connected with a cubic spline interpolation. The total sensitivity (GLOB, black line) has been split into separate sensitivities to fluxes applied over particular geographical regions: the Arctic (ARCT, red line), the North Atlantic (NATL, blue line), and the rest of the ocean (ROTO, purple line) as shown in the insert in panel (c). The relative contributions of the three regions (NATL, ARCT, and ROTO) to the total sensitivity are shown in panels (c) and (d). 


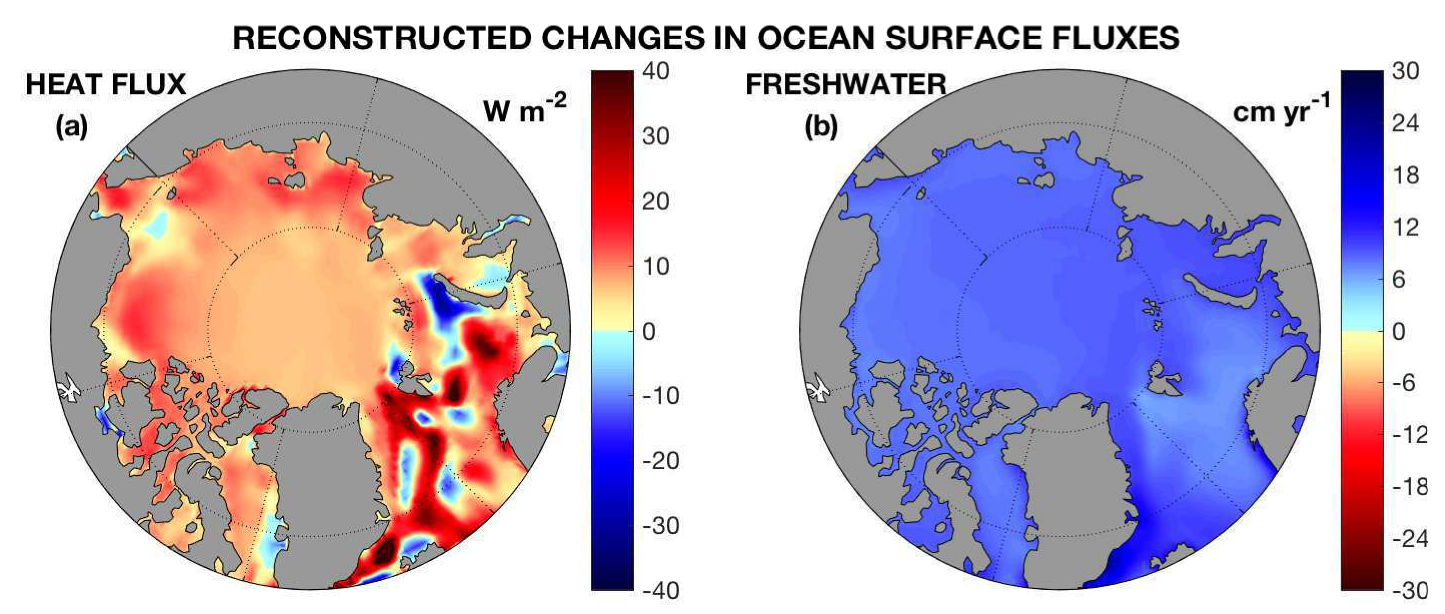

(c)

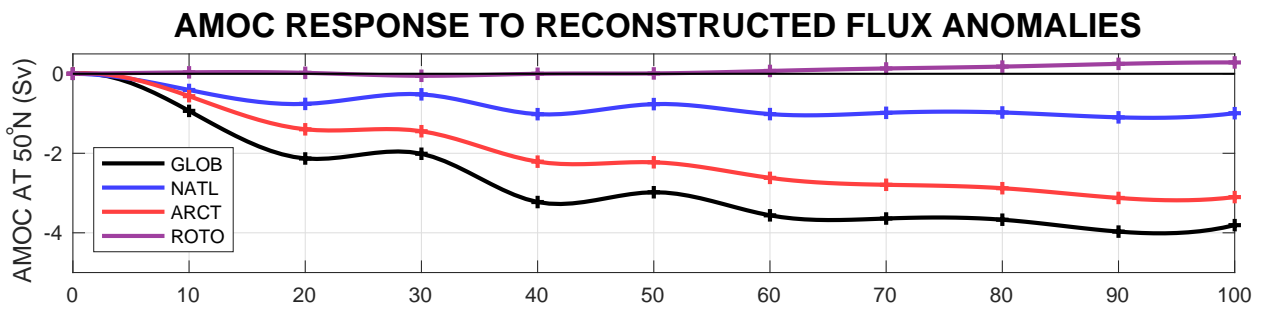

(d)

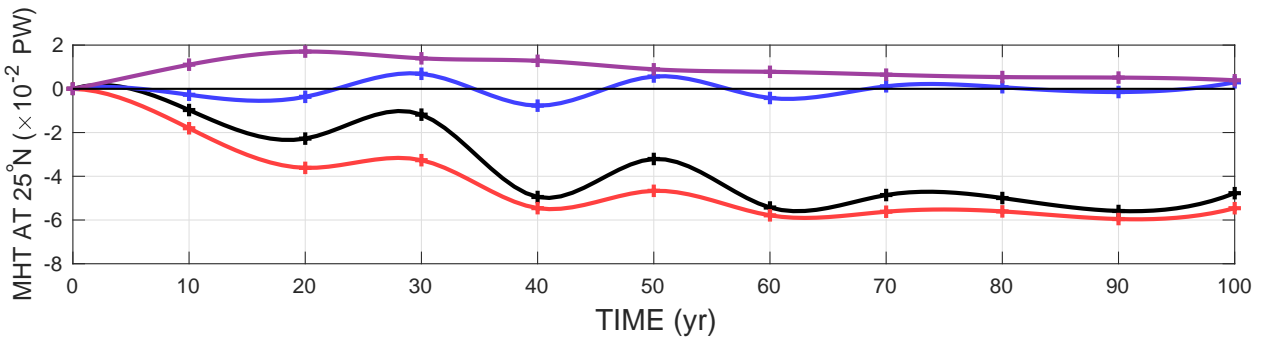

Figure 5: Estimated decadal changes in ocean surface fluxes and the model AMOC response. (a,b) Anomalies in surface fluxes of (a) heat and (b) freshwater reconstructed for the period 2004-2015 relative to 1988-1994, see Methods. Anomalies in heat fluxes are based on the ERA-INTERIM data ${ }^{37}$ modified here to allow for a global mean downward oceanic heat flux of $+0.55 \mathrm{~W} \mathrm{~m}^{-2}$. Anomalies in freshwater fluxes incorporate changes in the atmospheric hydrological cycle and the contributions from the melting Greenland ice sheet and Arctic sea ice (Fig. 1c), both uniformly distributed over the Arctic ocean. The resultant Arctic freshwater flux anomaly is spatially varying, but these variations are relatively small. These reconstructions indicate that the Arctic ocean has experienced a net warming of $8.2 \mathrm{~W} \mathrm{~m}^{-2}$ and a freshening of $8.7 \mathrm{~cm} \mathrm{yr}^{-1}$. $(\mathrm{c}, \mathrm{d})$ The model AMOC response to the reconstructed flux anomalies, maintained for 100 years, is presented in terms of (c) oceanic meridional volume transport at $50^{\circ} \mathrm{N}$ and (d) heat transport $(\mathrm{MHT})$ at $25^{\circ} \mathrm{N}$. Model results, obtained from the forward ocean GCM, are shown as small crosses connected by a cubic spline interpolation. The AMOC total response to the reconstructed fluxes (GLOB, black line) is again split into components due to three geographical regions: the Arctic (ARCT, red line), the North Atlantic (NATL, blue line) and the rest of the ocean (ROTO, purple line). 

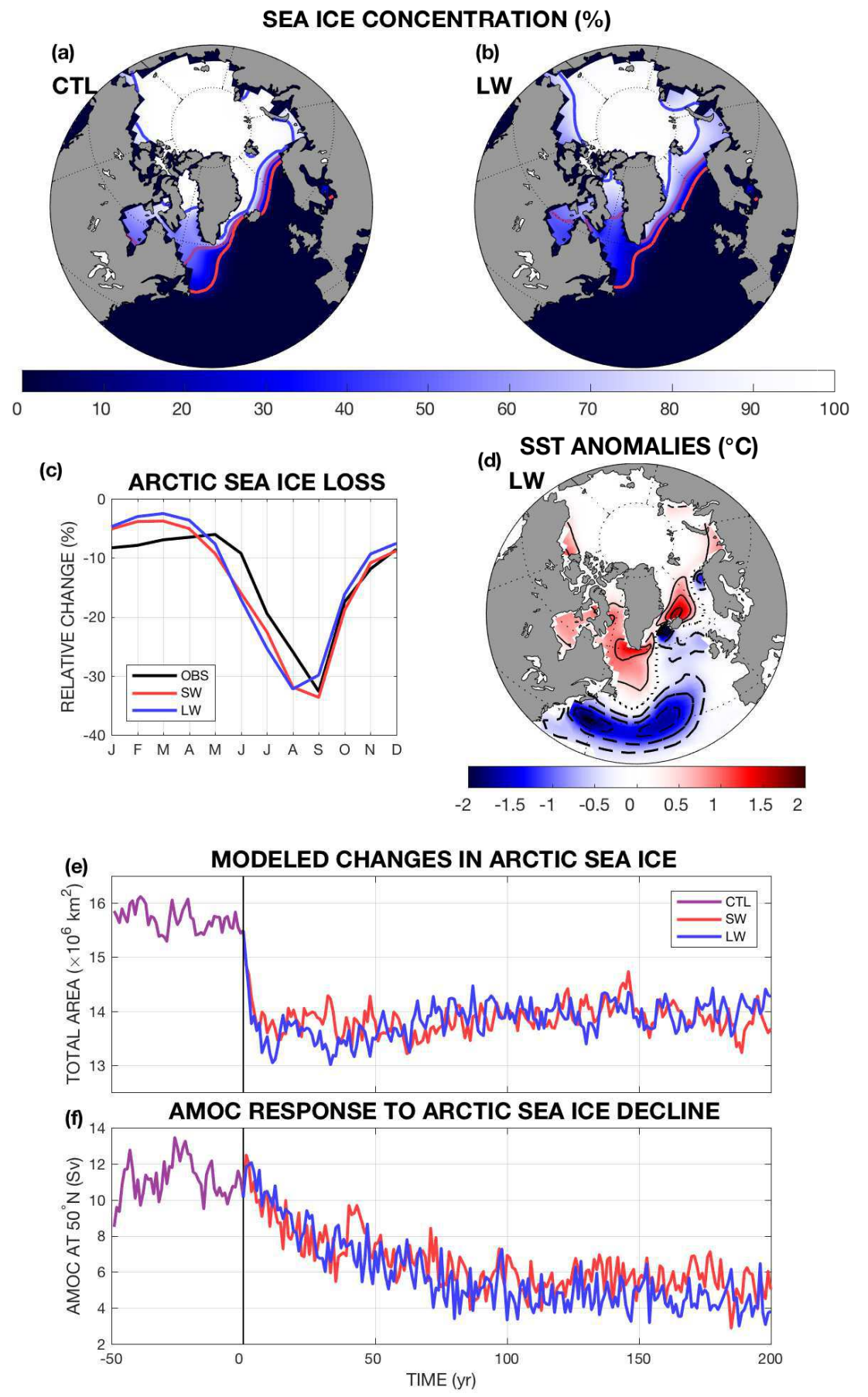

FIgURE 6: Arctic sea ice retreat and its impacts simulated by a climate GCM. The effects of sea ice decline are isolated within two experiments perturbing sea ice radiation balance: LW (reducing longwave emissivity of sea ice) and SW (reducing shortwave reflectivity). Both perturbation experiments start from the same preindustrial control (CTL). (a,b) Annual-mean sea ice concentration (in \%) in the CTL and LW experiments, and (d) SST anomalies in the latter simulation. The blue, purple and red contours mark $85 \%, 50 \%$, and $15 \%$ sea ice concentrations; SST contour intervals are $0.5^{\circ} \mathrm{C}$. (c) Relative decline (in \%) of sea ice total area for different months of the year in the observations (black line) and LW (blue) and SW (red) experiments. The observations reflect the difference between 2005-2014 and 1979-1988. Model output was averaged within the last 50 years of the CTL and withingyears 151-200 for the LW and SW experiments. $(\mathrm{e}, \mathrm{f})$ Total area of Arctic sea ice (in $10^{6} \mathrm{~km}^{2}$ ) and the AMOC volume transport $(\mathrm{Sv})$ at $50^{\circ} \mathrm{N}$ as a function of time in the CTL (purple), LW (blue) and SW (red) experiments. Perturbations to sea ice radiative balance are applied instantaneously at time zero and then maintained for the duration of each experiment (Methods). Note the multi-decadal timescale of AMOC adjustment. 
Arctic sea ice decline weakens the Atlantic Meridional

$$
\text { Overturning Circulation }
$$

Florian Sévellec, Alexey V. Fedorov, and Wei liu

Supplementary Information 
(a)

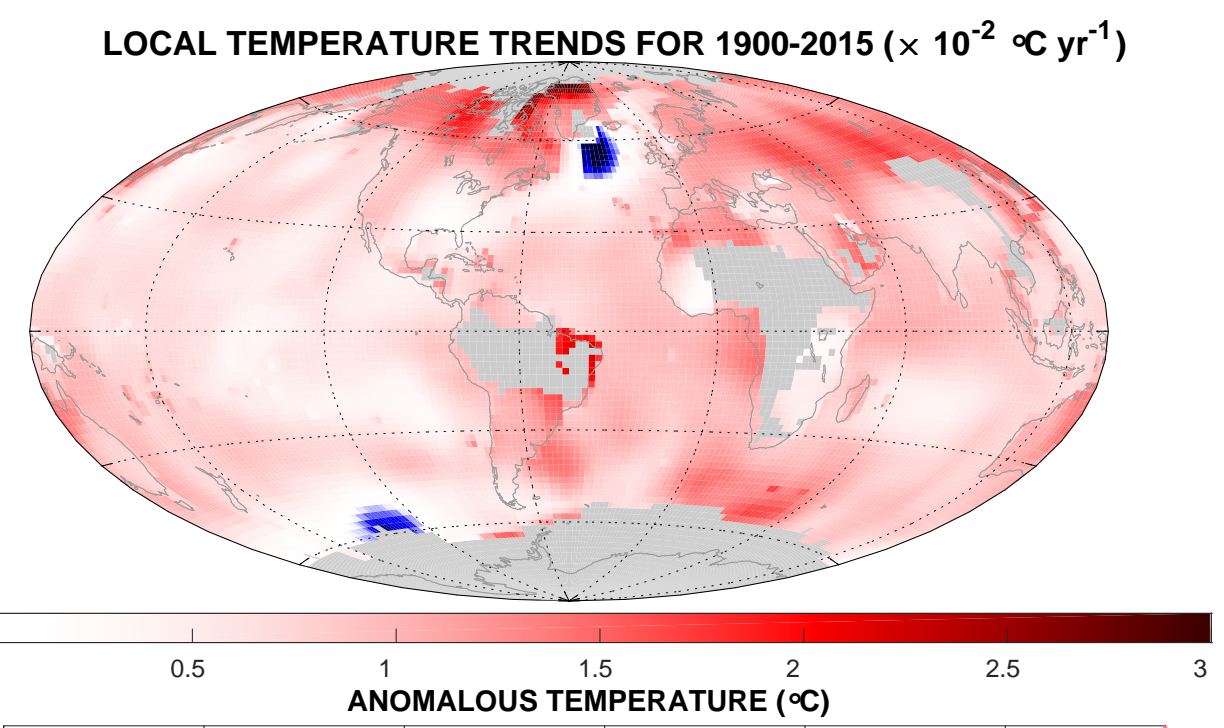

(b)

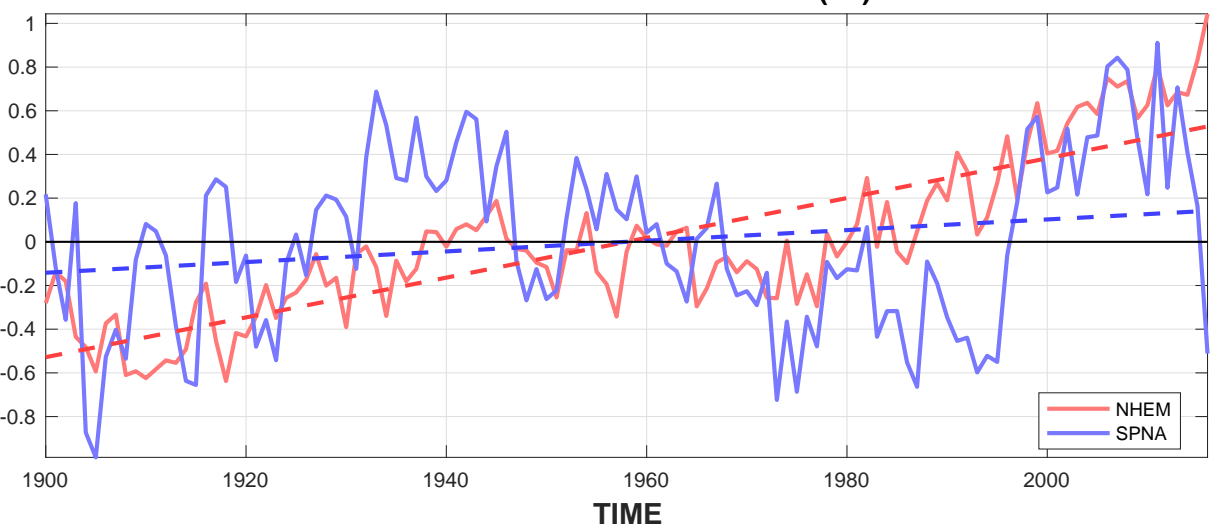

Figure S1: Temperature changes over the past century. (a) A global map of local surface air temperature trends between 1900 and 2015. The subpolar North Atlantic shows a generally weaker warming with a localized region of negative trend south of Greenland often referred to as the Warming Hole and conjectured to be caused by the AMOC slow-down ${ }^{3,4}$. NASA GISS temperature were used; gray indicates insufficient data. (b) Spatially-averaged temperature anomalies in the Northern Hemisphere (NHEM, red solid line) and the subpolar North Atlantic (SPNA, blue solid line) for the same period. Dashed lines indicate the corresponding linear trends. Here, the subpolar North Atlantic is defined as a rectangular region confined to $50^{\circ} \mathrm{W}-10^{\circ} \mathrm{W}$ and $50^{\circ} \mathrm{N}-60^{\circ} \mathrm{N}$. The warming trend is significantly weaker in the subpolar North Atlantic than that for the entire Northern Hemisphere, which suggests an AMOC slow-down. 


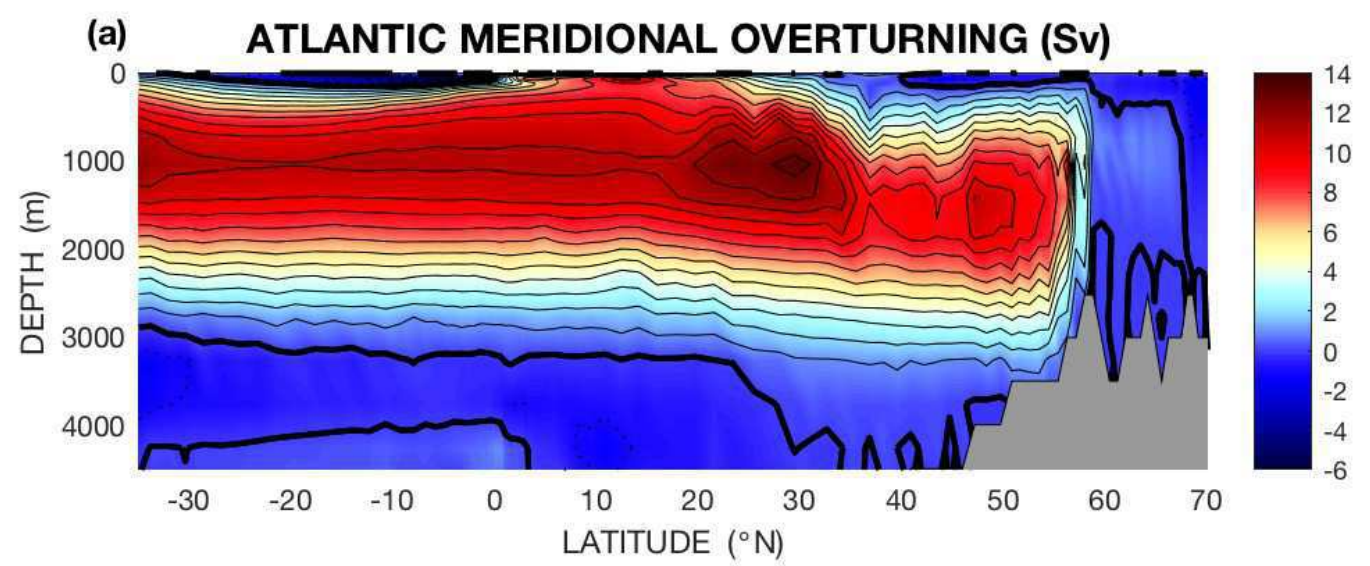

(b) ATLANTIC ZONALLY AVERAGED TEMPERATURE (Sv)
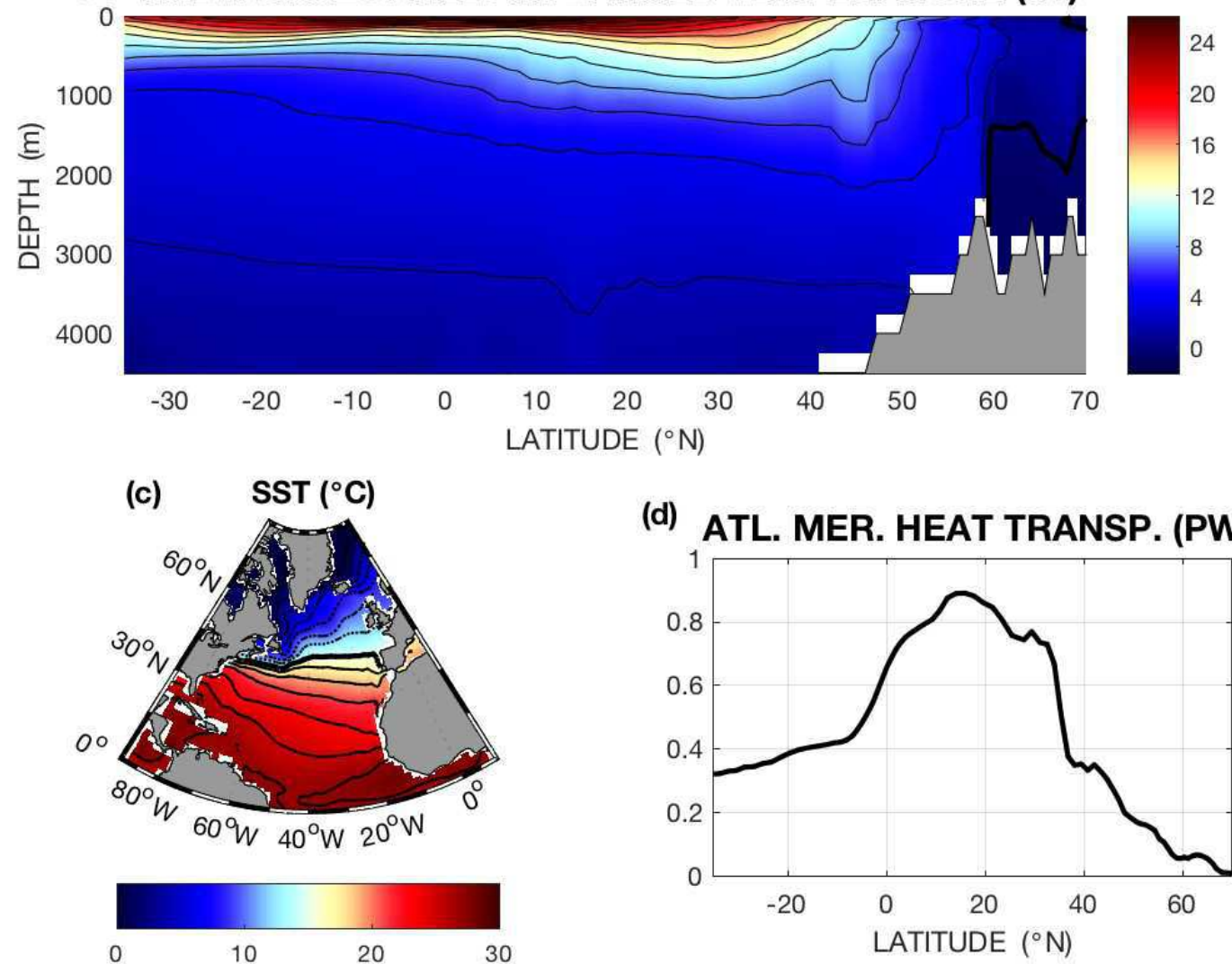

(d) ATL. MER. HEAT TRANSP. (PW)

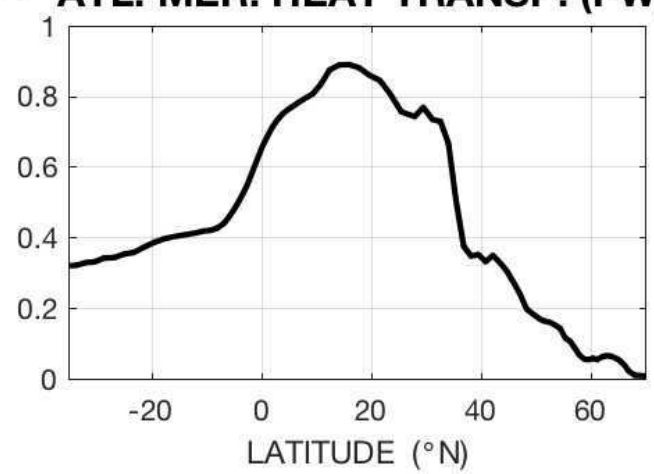

Figure S2: The climatological mean state of the Atlantic ocean as reproduced by the full ocean GCM. (a) Zonally averaged streamfunction showing the AMOC; contour intervals (CI) are $1 \mathrm{~Sv}$; the thick solid line corresponds to $0^{\circ} \mathrm{C}$, plain and dotted lines indicate higher and lower values, respectively. (b) Zonally averaged temperature; CI are $2^{\circ} \mathrm{C}$, the thick solid line corresponds to $0^{\circ} \mathrm{C}$, plain lines indicate higher values. (c) SST; CI are $2^{\circ} \mathrm{C}$, the thick solid line corresponds to $15^{\circ} \mathrm{C}$, plain and dotted lines indicate higher and lower values, respectively. (d) Meridional heat transport as a function of latitude. The figure is modified from Sévellec and Fedorov $(2015)^{23}$. 

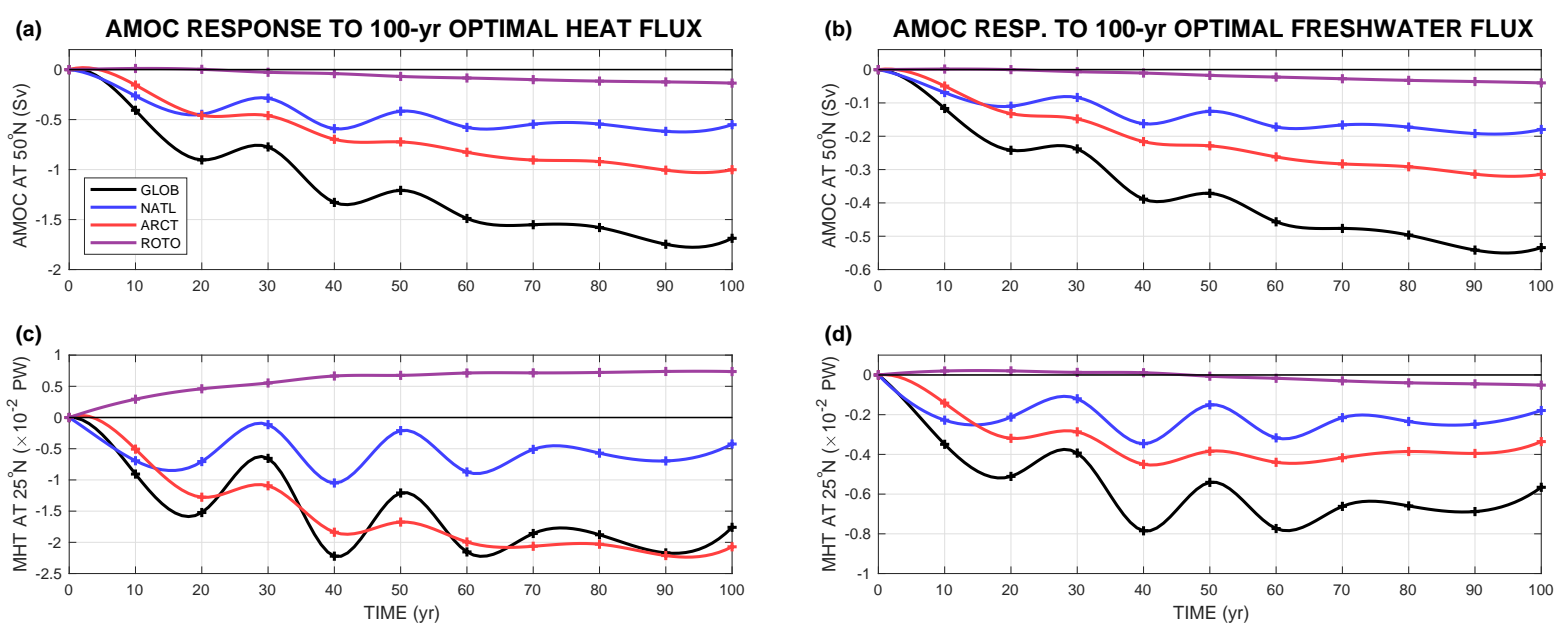

Figure S3: The AMOC response to the 100-yr optimal (left) heat and (right) freshwater fluxes. The plot describes changes in the Atlantic ocean $(a, b)$ meridional volume transport at $50^{\circ} \mathrm{N}$ and $1,500 \mathrm{~m}$ depth and (c,d) heat transport (MHT) at $25^{\circ} \mathrm{N}$ computed by the forward GCM after the optimal fluxes were imposed. The model results are shown as small crosses connected with a cubic spline interpolation. The corresponding patterns of the optimal fluxes were displayed in Fig. 3d and h. The AMOC decrease after $100 \mathrm{yr}$ is equal to the optimal impact of 100-yr heat and freshwater fluxes shown in Fig. 4a and b. The AMOC total response to the imposed fluxes (GLOB, black line) is again split into separate responses to fluxes applied over different geographical regions: the Arctic (ARCT, red line), the North Atlantic (NATL, blue line), and the rest of the ocean (ROTO, purple line). Note that the impacts of heat fluxes are several times greater. 


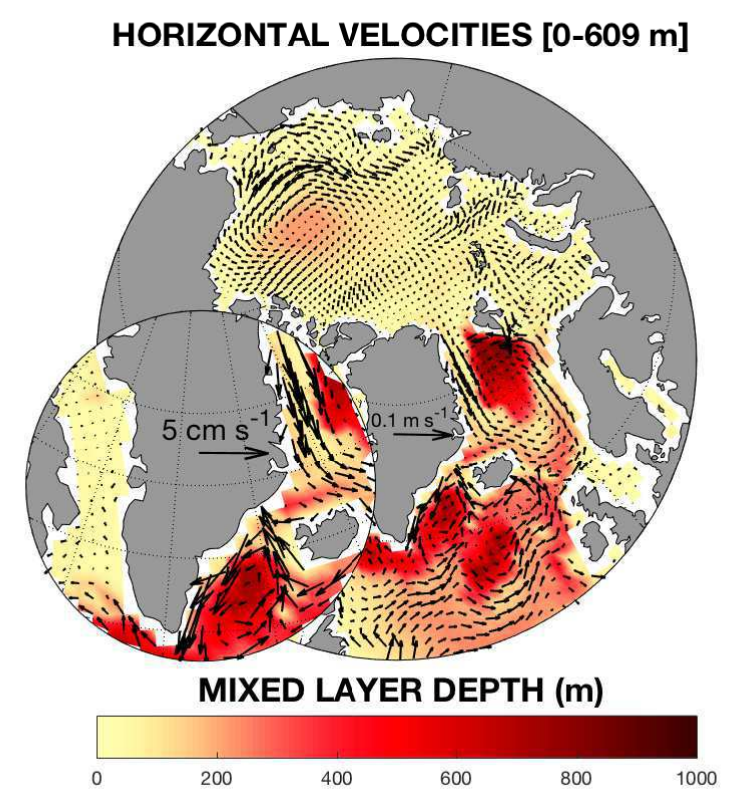

FIGURE S4: Ocean horizontal velocities and mixed layer depth for the climatological mean state of the full ocean GCM. A vertical average (from 0 to $609 \mathrm{~m}$ ) of the annual-mean horizontal velocity (arrows) and the depth of model ocean mixed layer (colors) are shown. Heat and freshwater anomalies are exported from the Arctic to the North Atlantic by the East Greenland current and the Greenland-Iceland ridge overflow, generating a net southward flow in the upper ocean. 

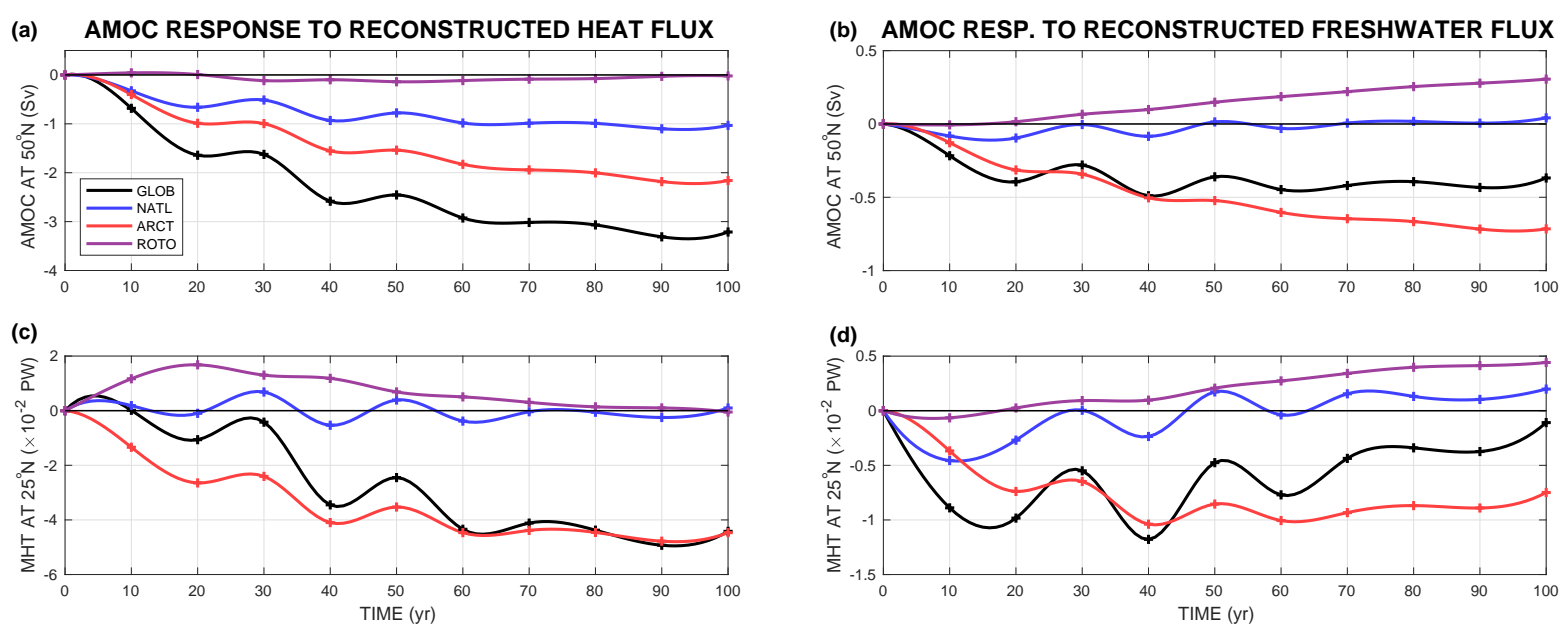

Figure S5: The model AMOC response to the observed flux anomalies. As in Fig. S3, but when we impose the reconstructed anomalies in (left) heat and (right) freshwater fluxes shown in Fig. 5a,b. The AMOC response to the combined anomalies was shown in Fig. 5c,d. 

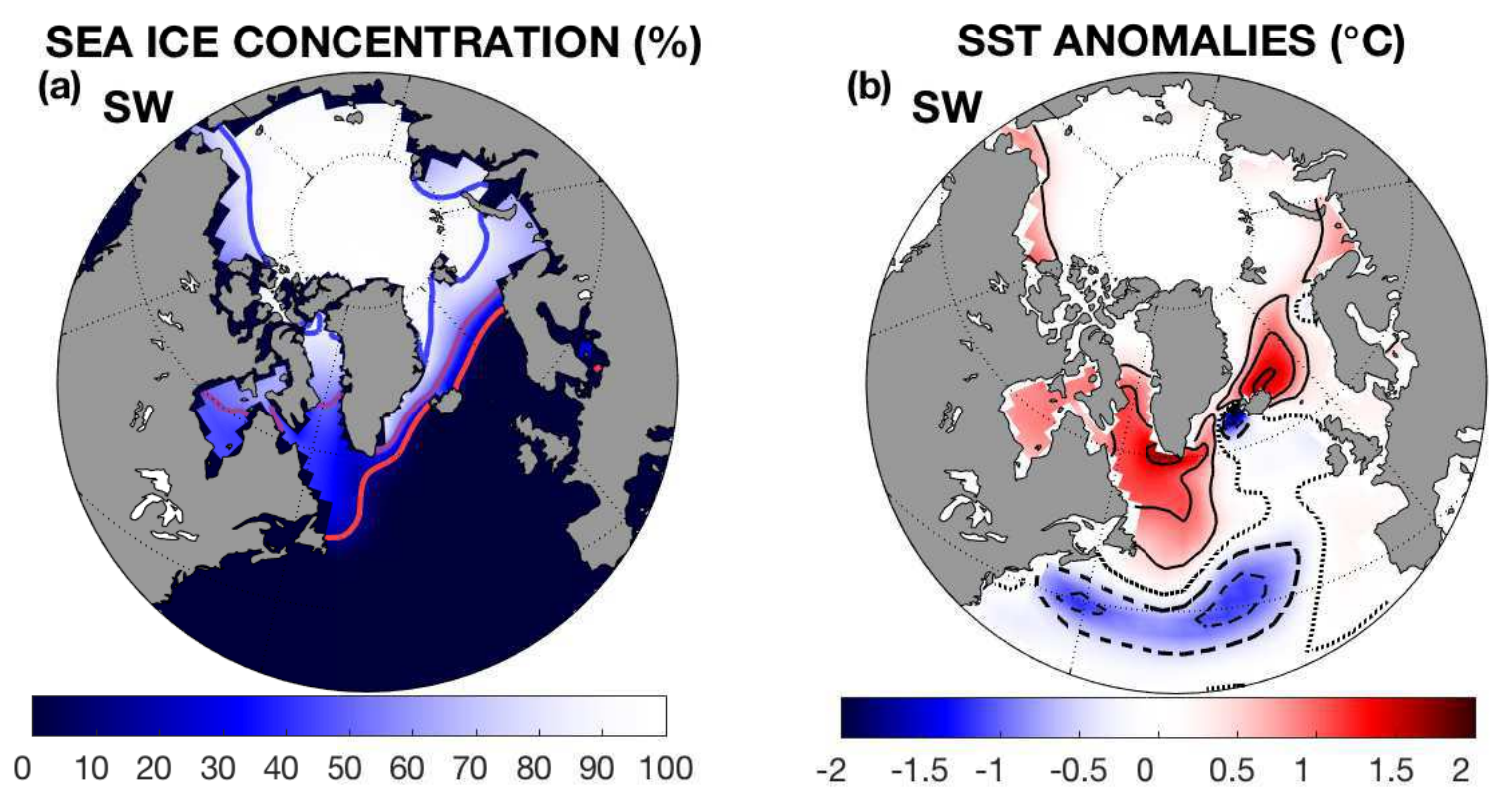

Figure S6: Arctic sea ice retreat and SST anomalies simulated by the climate GCM. As in Fig. 6b,d but for the SW experiment. 
SEPTEMBER SEA ICE CONCENTRATION (\%)
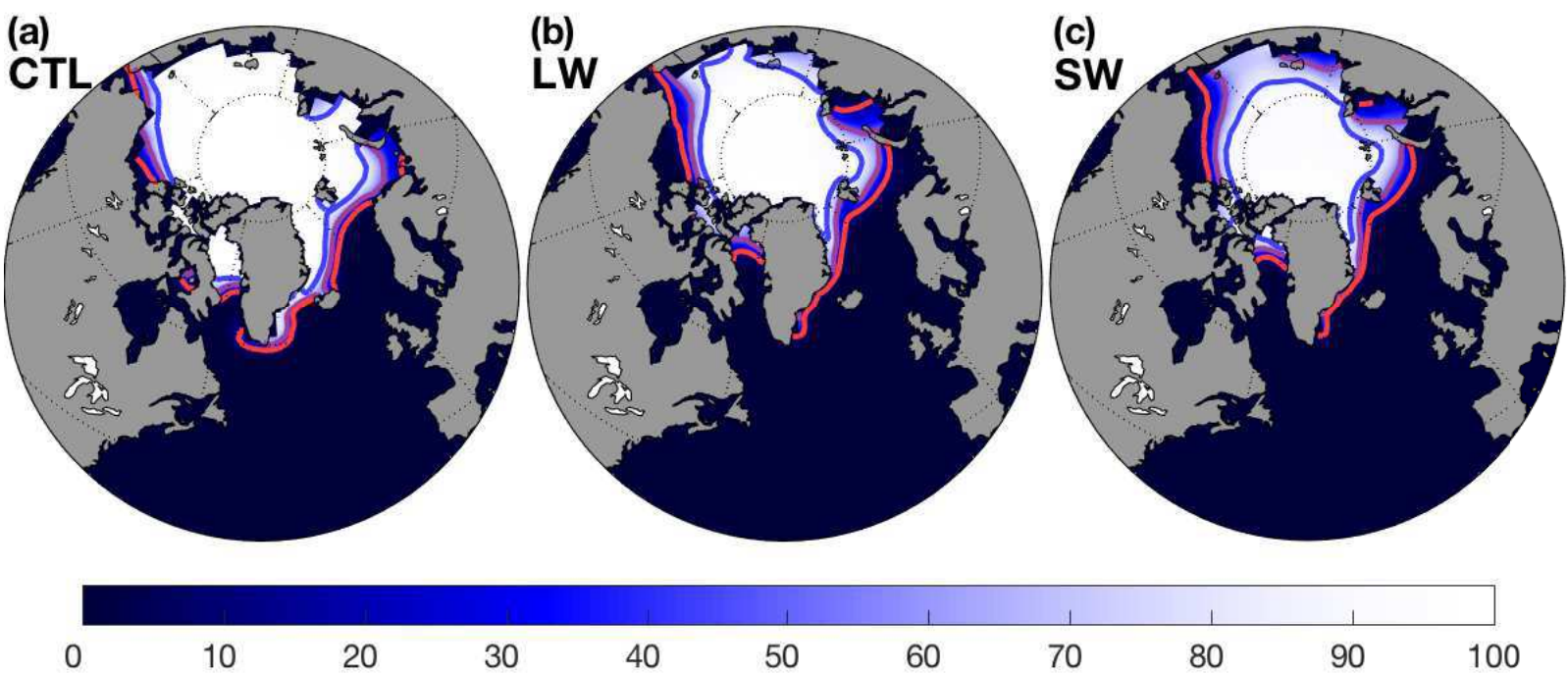

SEPTEMBER SST ANOMALIES $\left({ }^{\circ} \mathrm{C}\right)$
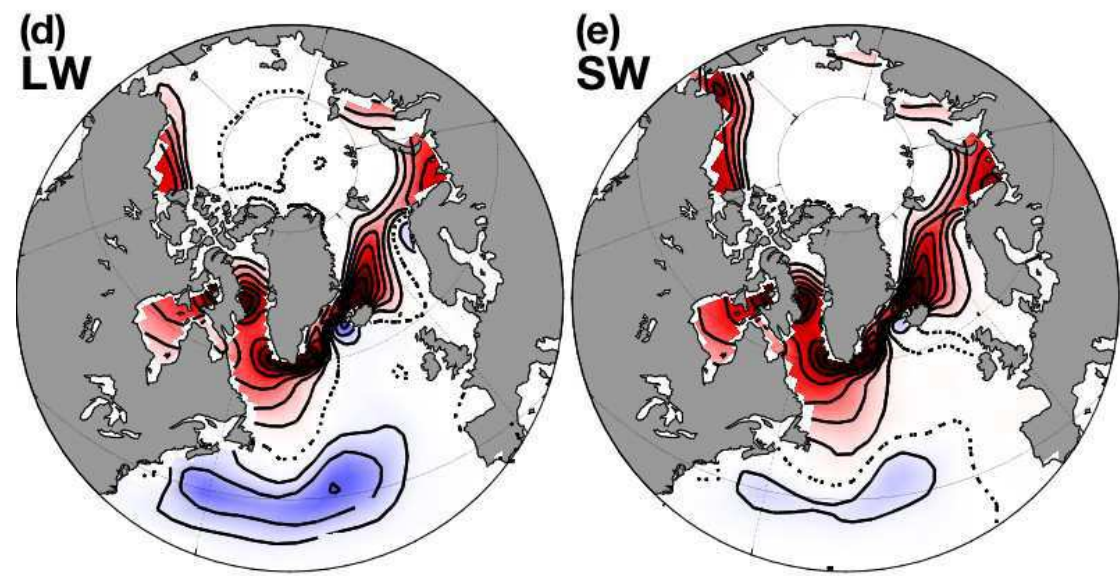

$\begin{array}{lllllllllllll}-3 & -2.5 & -2 & -1.5 & -1 & -0.5 & 0 & 0.5 & 1 & 1.5 & 2 & 2.5 & 3\end{array}$

FiguRE S7: Arctic sea ice retreat and SST anomalies simulated by the climate GCM during September. (a-c) September mean sea ice concentration for the CTL, LW and SW experiments. The blue, purple and red contours mark 85\%, 50\%, and $15 \%$ sea ice concentrations. (d,e) September SST anomalies (in ${ }^{\circ} \mathrm{C}$ ) for the $\mathrm{LW}$ and SW experiments with respect to the control SST contour intervals are $0.5^{\circ} \mathrm{C}$. Model output was averaged within the last 50 years of the CTL run, and within years 151-200 for the perturbation experiments (see Fig. S8). 

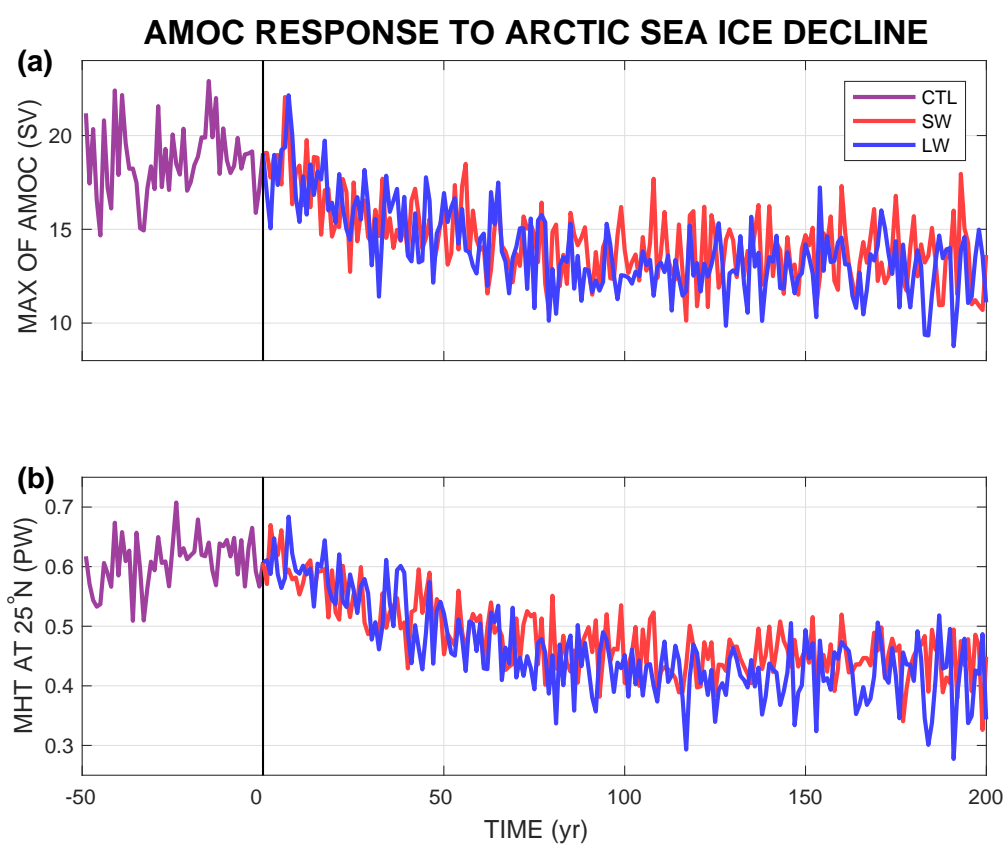

Figure S8: The impacts of Arctic sea ice retreat on the AMOC in the LW and SW coupled model experiments. (a) AMOC maximum volume transport (estimated between $10^{\circ} \mathrm{N}$ and $70^{\circ} \mathrm{N}$ and between $500 \mathrm{~m}$ and $5000 \mathrm{~m}$ ) and (b) oceanic meridional heat transport (MHT) at $25^{\circ} \mathrm{N}$. Both perturbations experiments start from the CTL run; modifications to sea ice radiative balance are imposed at time zero and maintained for the duration of each experiment. 